This item was submitted to Loughborough's Research Repository by the author.

Items in Figshare are protected by copyright, with all rights reserved, unless otherwise indicated.

\title{
Mechanical behaviour of nonwovens: analysis of effect of manufacturing parameters with parametric computational model
}

PLEASE CITE THE PUBLISHED VERSION

http://dx.doi.org/10.1016/j.commatsci.2013.12.040

\section{PUBLISHER}

(C) Elsevier B.V.

\section{VERSION}

AM (Accepted Manuscript)

\section{PUBLISHER STATEMENT}

This work is made available according to the conditions of the Creative Commons Attribution-NonCommercialNoDerivatives 4.0 International (CC BY-NC-ND 4.0) licence. Full details of this licence are available at: https://creativecommons.org/licenses/by-nc-nd/4.0/

\section{LICENCE}

CC BY-NC-ND 4.0

\section{REPOSITORY RECORD}

Farukh, Farukh, Emrah Demirci, Baris Sabuncuoglu, Memis Acar, Behnam Pourdeyhimi, and Vadim V. Silberschmidt. 2019. "Mechanical Behaviour of Nonwovens: Analysis of Effect of Manufacturing Parameters with Parametric Computational Model”. figshare. https://hdl.handle.net/2134/17002. 


\title{
Mechanical behaviour of nonwovens: Analysis of effect of manufacturing parameters with
} parametric computational model

\author{
Farukh Farukh $^{(1)}$, Emrah Demirci $^{(1)}$, Baris Sabuncuoglu ${ }^{(1)}$, Memiș Acar $^{(1)}$, Behnam Pourdeyhimi ${ }^{(2)}$, \\ *Vadim V. Silberschmidt ${ }^{(1)}$ \\ 1 - Wolfson School of Mechanical and Manufacturing Engineering, Loughborough University, UK \\ 2 - Nonwovens Cooperative Research Center, North Carolina State University, Raleigh, NC, USA \\ *Corresponding author's e-mail: $\underline{\text { V.Silberschmidt@lboro.ac.uk }}$ \\ Tell: +441509227504 ; fax: +441509227502
}

Add: Wolfson School of Mechanical and Manufacturing Engineering, Loughborough University, UK

Keywords: nonwoven; polypropylene; finite element; damage

\begin{abstract}
:
A deformation behaviour of, and damage in, polymer-based thermally bonded nonwovens was studied with a parametric finite-element model. Microstructure of the studied nonwoven was modelled by direct introduction of fibres and bond points, employing a subroutine-based parametric technique. This technique helped to implement variations in dimensional characteristics of structural entities related with manufacturing of these materials. Following experimental observations, a realistic orientation distribution of fibres and single-fibre failure criteria were included into the model. The developed model was demonstrated to be a very useful tool not only for predicting effects of parameters related to manufacturing of nonwovens or of specimen's size on a macroscopic response of the nonwoven but also for getting an insight into deformation mechanisms and damage localization in its structure.
\end{abstract}

\section{Introduction}

Nonwovens are engineered fabrics manufactured from a set of disordered fibres consolidated together by localized melting or by the use of chemicals. Simple entanglement of fibres is also possible by means of mechanical pressure using water or cold calendering. Nonwovens and their combinations with other materials are used in numerous applications, including geotextiles for soil reinforcement as well as products for medicine, filtration and aerospace industry [1]. Regardless of the application area of nonwovens, understanding of relationships between their micro/macro mechanical properties and manufacturing parameters is needed for tailoring their properties and performance.

Thermal bonding is the most commonly used technique for the manufacturing of nonwovens $[2,3]$. In thermally calender-bonded nonwovens, a fibrous web is passed through a hot calendar with an embossed pattern. Bonding mainly occurs at calender's raised areas resulting in bonded spots called "bond points". Other parts of the web, which were not in 
contact with the hot engraved pattern, remained unaffected and form the permeable part called fibre matrix that acts as a link between the bond points. The structure of resulting thermally bonded nonwoven (shown in Fig. 1) is a combination of continuous and discontinuous regions, thanks to which the material exhibits a unique and complex mechanical behaviour. This behaviour is highly affected by the variation in manufacturing parameters such as size, shape and pattern of bond points and orientation distribution of fibres as well as temperature and pressure variations. Generally, optimal bonding is implemented during manufacturing of nonwovens using pre-defined, fixed levels of bonding temperature, pressure and speed [4]. Therefore, the effects of temperature and pressure variations on mechanical performance of the fabric are not studied here.

Previously, several models employing various approaches were developed to simulate the mechanical behaviour of nonwovens [5-9]. All of the simulations regarding mechanical performance of nonwoven available in literature are limited to a particular type of nonwoven with fixed values of size, shape and pattern of bond points. To author's knowledge, the only simulations predicting the effect of various manufacturing parameters on mechanical behaviour of nonwovens were presented in [10]. However, the results were limited to initial deformation of the fabric without any analysis of the damage behaviour of the fabric. Moreover, the effects of orientation distribution of fibres on mechanical behaviour of the fabric in terms of stress/strain distribution in fibres were not studied. Additionally, that model does not account for structural evolution as a result of progressive failure of fibres since the fibre failure criteria were not incorporated in it. This information is important for analysis of mechanical performance and structural evolution of these materials during deformation and damage.

This study is aimed at the effects of dimensional and shape variability of bond points and specimen sizes on deformation and damage of low-density thermally bonded nonwovens based on monocomponent polymer fibres. Additionally, the role of orientation distribution of fibres in defining the mechanical performance of the fabric was investigated. The first part of this paper describes the suggested parametric technique used for development of a finiteelement model. The statistical parameters that define the fabric's microstructure as well as mechanical properties such as single-fibre behaviour and failure criteria, investigated experimentally [13], were used for the development of a realistic fabric's models. Mechanical performance of nonwovens was simulated using the developed models and validated with experimental data. Finally, conclusions based on the obtained results and applicability of the model to design nonwoven for specific application requirements are discussed.

\section{Modelling Technique}

A novel parametric finite-element modelling technique was developed to study the structureproperties relationship and the effect of various manufacturing parameters on deformation and damage of nonwovens. The parametric nature of the model allowed the introduction of variations in nonwoven's structure in a very efficient way, enabling the study of effect of various parameters on its mechanical behaviours. The details of the modelling process are given below. 


\subsection{Generation of Microstructure}

Nonwoven materials being a type of fibrous networks contain large numbers of fibres; these fibres are generally randomly oriented throughout their structure. These complexities make it difficult to develop a model of nonwoven network by explicit introduction of fibres using conventional modelling technique based on available operations with a pre-processor. Therefore, an efficient parametric modelling technique based on a subroutine was adopted in this study. In this technique, a computer builds up the model according to the instructions written in the code. The subroutine developed in this study allows reformulation of the model to incorporate variations in manufacturing parameters such as orientation distribution of fibres, size, shape and pattern of bond points, planar density of the fabric etc. into the model with significantly reduced efforts. Thus, it is possible to generate complex models of nonwoven fibrous network in a relatively short time. The subroutine was written in Patran Command Language (PCL), which can be read by commercial software MSC. Patran.

Starting from the internal structure, the subroutine develops the model by explicit introduction of fibres according to their orientation distribution function. Before starting the modelling process, input parameters required for modelling of nonwovens, such as physical and mechanical properties of fibres, their orientation distribution, size, shape and pattern of bond points are determined by experimental characterisation of the material. The details of determination of these material properties are given in [13]. The process of development of the model starts with introduction of bond points; they are modelled according to their required shape, size and pattern. Then, the actual full length of fibres $\left(L_{\mathrm{a}}\right)$ in the area of fabric corresponding to the model is determined by using the scheme given in [14]. Then, using the information on length of individual fibres, the total number of fibres in the model is calculated. After this, their total length $\left(L_{\mathrm{s}}\right)$ is calculated by assuming a random selection of starting points for introduction of fibres. The magnitude of the actual fibre length $\left(L_{\mathrm{a}}\right)$ and the simulated fibre length $\left(L_{\mathrm{s}}\right)$ are compared. The latter value can never be greater than the former one as some parts of the fibres in the model are outside the studied area since they were introduced randomly e.g. a portion of fibre B is outside the model area (Fig. 2). Therefore, the total number of fibres to be modelled is increased one by one until $L_{\mathrm{s}}=L_{\mathrm{a}}$. The calculation of the number of fibres is performed before the actual modelling process is started; this reduces significantly the time required to generate the model. The discussed procedure of calculation of the number of fibres is shown in the flow chart in Fig. 3.

After calculation of the number of fibres, the process of modelling of fibres according to their orientation distribution is started and continued until the full length of the fibre is introduced into the model. The complete details of the process of development of nonwoven network are given elsewhere [13, 14]. Following the morphological analysis of the fabric, the nonwoven model consists of two regions: bond points and fibrous matrix (Fig. 4). A flow chart showing the steps involved in generation of the network is given in Fig. 3.

\subsection{Finite-element model}

The generated model of nonwoven was discretised with finite elements. It was performed by using the subroutine, ensuring that each fibre was properly attached with the bond points at its ends to avoid convergence issues. Each fibre in the model was presented with a single 

anumber of shell elements (Element 139 in MSC. Marc).

Mechanical and geometrical properties of the fibres and bond points obtained previously [13] were implemented in the developed model. The constituent fibres are made of polymer materials with nonlinear elastic-plastic and viscous properties. A single-fibre failure criterion based on experimental data $[13,17]$ was used to simulate damage initiation and propagation in nonwovens. The developed model captured the random, anisotropic nature of the fabric, based on explicit introduction of fibres, reproduced its main deformation and damage mechanisms observed experimentally. The simulations of tensile tests were performed by fixing the nodes on one end of the model. In order to allow the comparison of simulation results with the experimental data, displacement-rate conditions, similar to the experiments, were applied in the axial directions on the nodes on other end of the model (see Fig. 4). All these processes were carried out by the subroutine as shown in Fig. 3 .

\section{Results and discussions}

A series of numerical simulations were implemented using the developed model. The simulation results were compared with the corresponding experimental data using forceextension graphs. In order to reduce the overall computing time while making sure that the size of the model specimen was sufficient enough to capture the mechanisms of deformation and damage, the gauge length in actual tests and corresponding simulations was kept larger than $15 \mathrm{~mm}$. Quasi-static loading conditions with strain rate of $0.1 \mathrm{1} / \mathrm{s}$ were used in numerical simulations and experiments. The variations of parameters was planned in such a way that it could elucidate the effects of major manufacturing and testing parameters on the fabric's deformation and damage behaviours, and show the capability of the model to be extended to other fibrous networks.

\subsection{Effect of specimen's size}

In the first case study, a $20 \mathrm{~g} / \mathrm{m}^{2}$ nonwoven fabric was chosen as sample material, and finiteelement models of different dimensions were developed as the fabric's behaviour depends upon its size [16]. The specimen wqidth varied from $5 \mathrm{~mm}$ to $15 \mathrm{~mm}$ whereas the gauge length was kept constant at $16.5 \mathrm{~mm}$. Geometric properties such as bond point size, shape, pattern (Pattern 1 in Table 1) and ODF obtained experimentally were implemented in the models. The single-fibre failure criterion obtained in a previous study [13] was implemented in the models to simulate damage. The main results obtained with simulations are presented in Fig. 5. As expected, the maximum strength of the fabric is nearly linearly proportional to the width of the specimen, and simulations with the developed models reproduced this feature. Besides, the gradual reduction in stiffness caused by progressive failure of fibres was obtained by the simulations similar to the experimental observations. Obviously, the scatter in experimental results was not present in the simulation results, obtained for a single statistical realisation. However, by considering the possible sources of scatter such as different realisation at the fibre placements in specimens as well as the variation in constituent fibre material properties and variation in their diameter will lead to scatter in numerical results. The overall shapes of deformed fabric during extension at strain of 0.5 with distribution of stresses in fibres and bond points are shown in Figs. 10(a-c) and 11(a-c), respectively. 
There is a large scatter in experimental results due to the reason mentioned in literature [6, variation, the FE model's response for each specimen size is within the range of the experimental results. This shows that the model is capable to predict the changes in the mechanical response of the fabric linked to variation in the specimen size. Additionally, a long tail of the force-extension graph after the maximum force carried by the web was obtained with the FE models; it is similar to that in the experimental data and can be attributed to progressive failure of fibres. This shows the capability of the model to predict the softening fabric's response as a result continuing damage and fracture development, thanks to the explicit introduction of fibres into the developed model.

\subsection{Effect of fabric density}

At the next stage of the study, the effect of variation of fabric's planar density on its stiffness, deformation and damage behaviours was analysed. Here, the $20 \mathrm{~g} / \mathrm{m}^{2}$ nonwoven, discussed above, was used as reference. A fabric with $30 \mathrm{~g} / \mathrm{m}^{2}$ planar density was chosen for this study. The size, shape and pattern of bond points of these fabrics were those of pattern 1 in Table 1. The FE model of a sample with dimensions $10 \mathrm{~mm}$ (width) $\times 16.5 \mathrm{~mm}$ (gauge length) (similar to the one of the sizes in our previous study for direct comparison) was developed using the parametric code. The strain rate of $0.11 / \mathrm{s}$ was used for the axial extension. The results obtained for this case are shown in Fig. 6. Apparently, stiffness and strength of the fabric increased with increasing planar density as compared to the reference model. The main deformation mechanism of nonwovens, such as reorientation of fibres along loading direction and increasing participation in load bearing [13], were observed in the model. The results predicted with the model in terms of force-extension graphs were in good agreement with the experimental data (Fig. 6). It shows the capability of the model to predict not only the microscopic behaviour of the fabric for various planar densities but also to estimate its macroscopic response depending upon this parameter. The deformed model demonstrating distributions of stresses in fibres and bond points is given in Figs. 10d and 11d, respectively.

The comparison between Figs. 5b and 6 demonstrated the effect of fabric's planar density on its mechanical behaviour. Since the models were based on direct introduction of fibres providing insight into the deformation and damage mechanisms of the nonwovens [13, 14], it was observed that these mechanisms and the sequence of their realisation remained the same regardless of their planar density.

\subsection{Effect of shape and pattern of bond points}

Another case study was performed to access the effect of shape and pattern of bond points on the fabric's mechanical behaviour and model's capability to predict it. A $30 \mathrm{~g} / \mathrm{m}^{2}$ nonwoven fabric with the size, shape and pattern of bond points presented as pattern 2 in Table 1 was developed. Dimensional parameters of the model were similar to those of the actual fabric of $30 \mathrm{~g} / \mathrm{m}^{2}$ (Figs. 7a and $7 \mathrm{~b}$ ) so that the experimental results could be used for the validation of simulations. In order to maintain the consistency and provide basis for direct comparison, the model with dimensions used in the previous study (10 $\mathrm{mm}$ width and $16.5 \mathrm{~mm}$ gauge length) was developed and strain rate of 0.11 was applied as boundary condition. The simulations were performed and the results in the form of force-extension graph were compared with the experimental data (Fig. 8); a good agreement was found between them. The modelled specimen of the nonwoven at different levels of extension is shown in Figs. 10e and 11e. 
As it can be observed by comparing Figs. 6 and 8, the fabric with diamond-shaped bond points demonstrated a stiffer behaviour as compared to that of the fabric with square-shaped bond points. The reason for this phenomenon lies in the fact that the fraction of area of the fabric covered by bond points in the former one (15\%) was more than that of the latter one $(14 \%)$. These results are consistent with previous studies $[10,15]$ showing that the fabric with a higher area covered by bond points is stiffer. Thus, the developed model can predict the behaviour of the fabric with arbitrary shape, size or pattern of bond points. Since various shapes, sizes and pattern of bond points can be adopted during the manufacturing of nonwovens, this model can be exploited to tailor nonwovens for better strength and reliability without involving resource-intensive (in terms of time and money) trial-and-error stages.

\subsection{Effect of orientation distribution of fibres}

In this part of the study, the effect of orientation distribution of fibres within the fabric on the overall deformation and damage was investigated. Using the parametric model, like one discussed above, various orientation-distribution functions can be introduced into the model to study their effect on mechanical behaviour of the fabric. However, in order to make the study tractable and to provide in-depth analysis, only one ODF which was used for the model of the $20 \mathrm{~g} / \mathrm{m}^{2}$ nonwoven with square-shaped bond point is discussed below in detail.

Due to heterogeneity and randomness of microstructure of nonwoven materials, strain levels of fibres at any level of extension of the fabric are different from its global strain. In each fibre, level of strain and corresponding stress during fabric's extension process depend upon its position and orientation in the structure. Cumulative distribution function for the calculated stresses in fibres for increasing levels of fabric's extension is shown in Fig. 9.

According to Fig. 9, stresses in more than 80 percent of fibres were below $70 \mathrm{MPa}$ and 120 $\mathrm{MPa}$ whereas the maximum level was approximately $100 \mathrm{MPa}$ and $180 \mathrm{MPa}$ at $25 \%$ and $50 \%$ of global extension, respectively. However, after this level of fabric's extension (i.e. $75 \%$ and $100 \%$ ), the stresses in 80 percent of fibres were approximately $60 \mathrm{MPa}$ and $30 \mathrm{MPa}$ at $75 \%$ and $100 \%$ extension of fabric, respectively. The maximum levels of stresses in fibres at $75 \%$ and $100 \%$ extension of fabric were approximately $310 \mathrm{MPa}$ and $350 \mathrm{MPa}$, respectively. This shows that stresses in fibres increased with increasing strain in the fabric initially. However, after a certain level of fabric's extension (50\%), the fraction of fibres at higher levels of stress started decreasing. The reason for this phenomenon lies in progressive failure of fibres with stretching. On fabric's extension, participation of fibres in load bearing increased and they fail progressively on reaching their stress or strain threshold. Due to such load failures, the load transferred to the remaining fibres around the failed ones causing higher stresses in them. However, these failures of fibres also resulted in an attempt by parts of the fabric to regain their original, un-stretched structure. This causes the decrease in stresses in a large number of fibres as shown in Fig. 9. Therefore, only a small portion of fibres participate in load bearing as fibre failure process starts. A more uniform distribution of stresses and strains in fibres could resolve this issue and result in better mechanical performance of nonwoven. This can be obtained by adjusting the orientation distribution of fibres in nonwoven fabric. Thus, apparently, orientation distribution of fibres has a significant effect of deformation and especially damage behaviour of the nonwoven fabric. Besides, more uniform distributions of 
stresses and strains in fibres could lead to more robust nonwoven structure by exploiting the parametric capabilities of the developed modelling approach. The distribution of stresses in fibres for variety of specimen sizes, planar densities and shapes, sizes and patterns of bond points are provided in Fig. 10. The corresponding stresses in bond points at that level of fabric's extension are provided in Fig. 11.

The stress pattern in each bond point can be calculated using the developed FE models, this is very important from a fundamental point of view, as fibres always fail at the periphery of bond points in thermally bonded nonwovens. Furthermore, a number of fibres are attached at each bond point, which means that the failure of a bond point during the deformation process of nonwoven would be catastrophic. Information about distribution of stresses in fibres and bond points, which is vital for deformation and, especially, damage analysis of the fabric, cannot be obtained with continuous FE models or easily from the experiments.

Another interesting observation, based on simulations, was misalignment of bond points in all the models that increasing with fabrics strain; a similar behaviour was observed in stretched real-life nonwovens (Fig. 12). This behaviour is caused by connection of a random number of randomly orientated fibres attached to bond points. Explicit introduction of such fibres into the model make it possible to simulate this behaviour, which is impossible with a continuous model.

\section{Conclusions}

The effect of various parameters on deformation and damage behaviours of bonded fibrous networks and distribution of stresses in fibres was elucidated by employing a specially developed parametric finite-element models. The results obtained with models were validated by experimental data.

To authors' knowledge, it is the first time that a parametric finite-element modelling approach is used to predict the effect of various manufacturing and structural parameters not only on deformation but also damage behaviour of the nonwoven fabric. Additionally, thanks to explicit introduction of fibres into model, it provides insights into mechanisms involved in fabric's deformation and damage along with information about distribution of stresses in fibres and bond points. This information cannot be achieved by using models based on continuum modelling technique or from the experiments. Hence, this model can be used to predict the localization of damage and structural evolution linked to fabric's extension. All this information obtained with the developed models is crucial for tailoring properties and performance.

The efficiency of the approach is exhibited in this study by perturbing some model's parameters and comparing the numerical prediction with experimental results. The capability of the model to cope with variation in manufacturing parameters such as size, shape and pattern of bond points, planar density of the fabric, orientation distribution of the fibres and testing parameters such as specimen size shows that the use of the model can be extended to all types of thermally bonded nonwovens as well as other types of fibrous networks. Since the effect of manufacturing parameters can be studied with this model, as mentioned in corresponding sections, it is a potential tool for the industry to design and optimise the mechanical properties of their nonwoven products. The model can be extended to predict the 
macroscopic response accounting for mechanisms of deformation and damage as well as more complex loading conditions.

\section{References}

[1] S. Batra, B. Pourdeyhimi, Introduction to Nonowvens Technology, DEStech Publications, 2012.

[2] S. J. Russell, Handbook of Nonwovens, Woodhead Publishing Limited, 2007.

[3] W. Albrecht, H. Fuchs, W. Kittelmann, Nonwoven fabrics: Raw Materials, Manufacture, Applications, Characteristics, Testing Processes, Wiley-VCH Weinheim, 2003.

[4] S. Michielsen, B. Pourdeyhimi, P. Desai, J. Appl. Polymer Sci. 99 (2006) 2489-2496.

[5] X. Hou, M. Acar, V.V. Silberschmidt, Comput. Mater. Sci. 46 (2009) 700-707.

[6] X. Hou, M. Acar, V.V. Silberschmidt, Comput. Mater. Sci. 50 (2011) 1292-1298.

[7] E. Demirci, M. Acar, B. Pourdeyhimi, V.V. Silberschmidt, Comput. Mater. Sci. 50 (2011)1286-1291.

[8] E. Demirci, M. Acar, B. Pourdeyhimi, V.V. Silberschmidt, Comput. Mater. Sci. 52 (2012)157-163.

[9] A. Ridruejo, C. González, J. LLorca, J. Solids Struct. 49 (2012) 2215-2229.

[10] B. Sabuncuoglu, M. Acar, V. V .Silberschmidt, Comput. Mater. Sci, 64 (2012) 192-197.

[11] F. Farukh, E. Demirci, B. Sabuncuoglu, M. Acar, B. Pourdeyhimi, V. V. Silberschmidt, Comput. Mater. Sci. 64 (2012) 112-115.

[12] B. Sabuncuoglu, M. Acar, V. V .Silberschmidt, Int. J. Numer. Meth. Engg., 94 (2013) 441-453.

[13] F. Farukh, E. Demirci, M. Acar, B. Pourdeyhimi, V.V. Silberschmidt, J. Mater. Sci. 48 (2013) 2334-2345.

[14] F. Farukh, E. Demirci, B. Sabuncuoglu, M. Acar, B. Pourdeyhimi, V. V. Silberschmidt, Comput. Mater. Sci. 71 (2013) 165-171.

[15] G.S. Bhat, P.K. Jangala, J.E. Spruiell, J. App. Poly. Sci. 92 (2004) 3593-3600.

[16] X. Hou, M. Acar, V.V. Silberschmidt, J. Engineered Fibers Fabrics, 4 (2009) 26-33.

[17] F. Farukh, E. Demirci, M. Acar, B. Pourdeyhimi, V. V. Silberschmidt, J. Physc: conf. Ser. 382012018. 


\section{Figures Captions}

Fig.1. Microscopic image of thermally bonded nonwoven

Fig. 2. Fibres inside and partially outside studied fabric area

Fig. 3. Flow chart of model development

Fig. 4. Developed finite-element model for $20 \mathrm{~g} / \mathrm{m}^{2}$ nonwoven

Fig. 5. Comparison of FE model and experimental results models of $20 \mathrm{~g} / \mathrm{m}^{2}$ nonwovens with various widths (a) $5 \mathrm{~mm}$; (b) $10 \mathrm{~mm}$; (c) $15 \mathrm{~mm}$ (shaded areas represent scatter in experimental results; continuous lines represent FE model responses)

Fig. 6. Comparison of FE model and experimental results of uniaxial tensile test for $30 \mathrm{~g} / \mathrm{m}^{2}$ nonwoven with square shape bond points (shaded area represents scatter in experimental results and continuous line represents FE model response)

Fig. 7. SEM image of $30 \mathrm{~g} / \mathrm{m}^{2}$ nonwoven material with diamond-shaped (a) and rectangularshaped (c) and corresponding part of FE models with diamond-shaped (b) and rectangular-shaped $(\mathrm{d})$ bond points

Fig. 8. Comparison of FE model and experimental results of uniaxial tensile test for $30 \mathrm{~g} / \mathrm{m}^{2}$ nonwoven with diamond-shaped bond points (shaded area represents scatter in experimental results; continuous line represent FE model response)

Fig. 9. Distribution of stresses in fibres for various level of global fabric extension

Fig. 10. Distribution of axial stress in $(\mathrm{MPa})$ in nonwoven structure at fabric's extension of 50\%: (a) $5 \mathrm{~mm}$ width; $20 \mathrm{~g} / \mathrm{m}^{2}$; (b) $10 \mathrm{~mm}$ width; $20 \mathrm{~g} / \mathrm{m}^{2}$; (c) $15 \mathrm{~mm}$ width; $20 \mathrm{~g} / \mathrm{m}^{2}$; (d) $30 \mathrm{~g} / \mathrm{m}^{2}$; square-shaped bond points; (e) $30 \mathrm{~g} / \mathrm{m}^{2}$; diamond-shaped bond points

Fig. 11. Dislocation and distribution of von Mises stress in $(\mathrm{MPa})$ in bond points at fabric's extension of $50 \%$ : (a) $5 \mathrm{~mm}$ width; $20 \mathrm{~g} / \mathrm{m}^{2}$; (b) $10 \mathrm{~mm}$ width; $20 \mathrm{~g} / \mathrm{m}^{2}$; (c) $15 \mathrm{~mm}$ width; $20 \mathrm{~g} / \mathrm{m}^{2}$; (d) $30 \mathrm{~g} / \mathrm{m}^{2}$; square-shaped bond points; (e) $30 \mathrm{~g} / \mathrm{m}^{2}$; diamond-shaped bond points

Fig. 12. Misalignment of bond points in $20 \mathrm{~g} / \mathrm{m}^{2}$ nonwoven at $50 \%$ of fabric's extension (arrows indicate fracture zones) 


\section{$\underline{\text { Tables }}$}

Table 1. Parameters of geometry and patterns of bond points

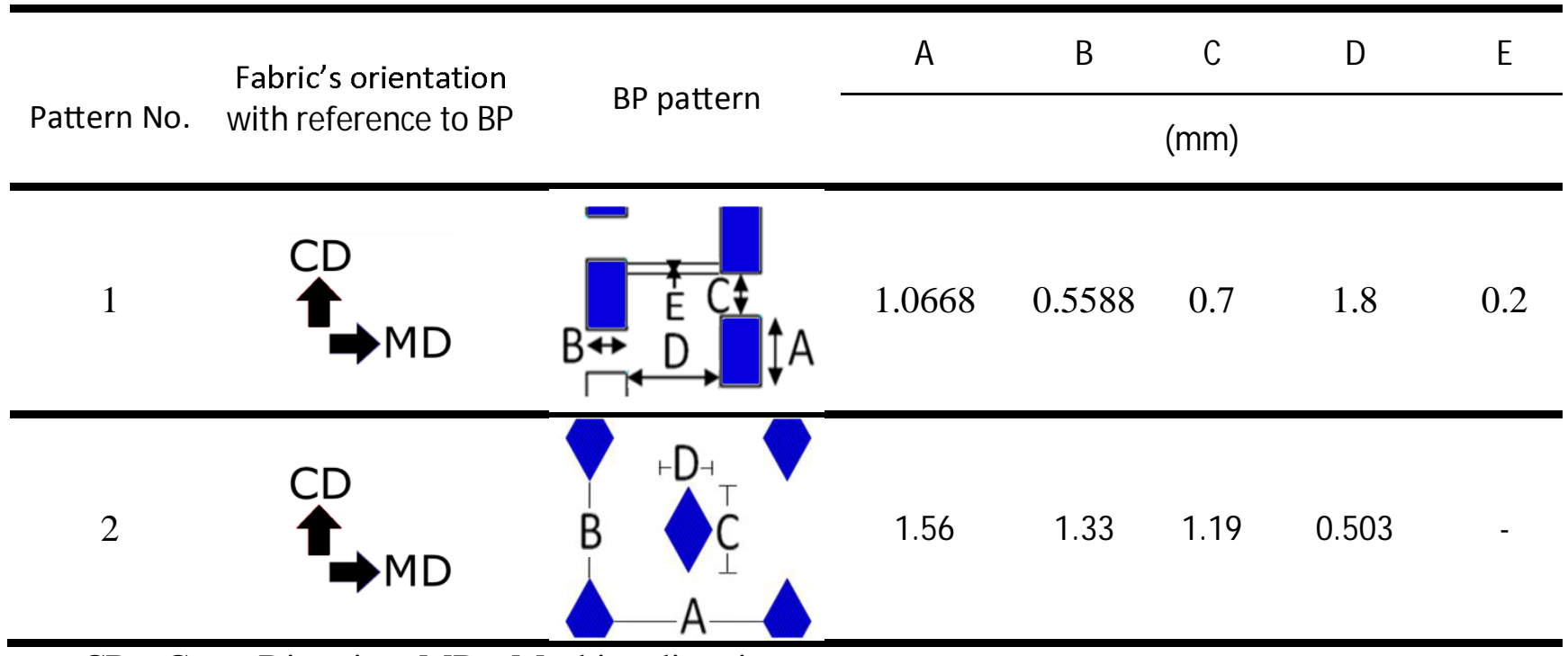

CD - Cross Direction, MD - Machine direction 


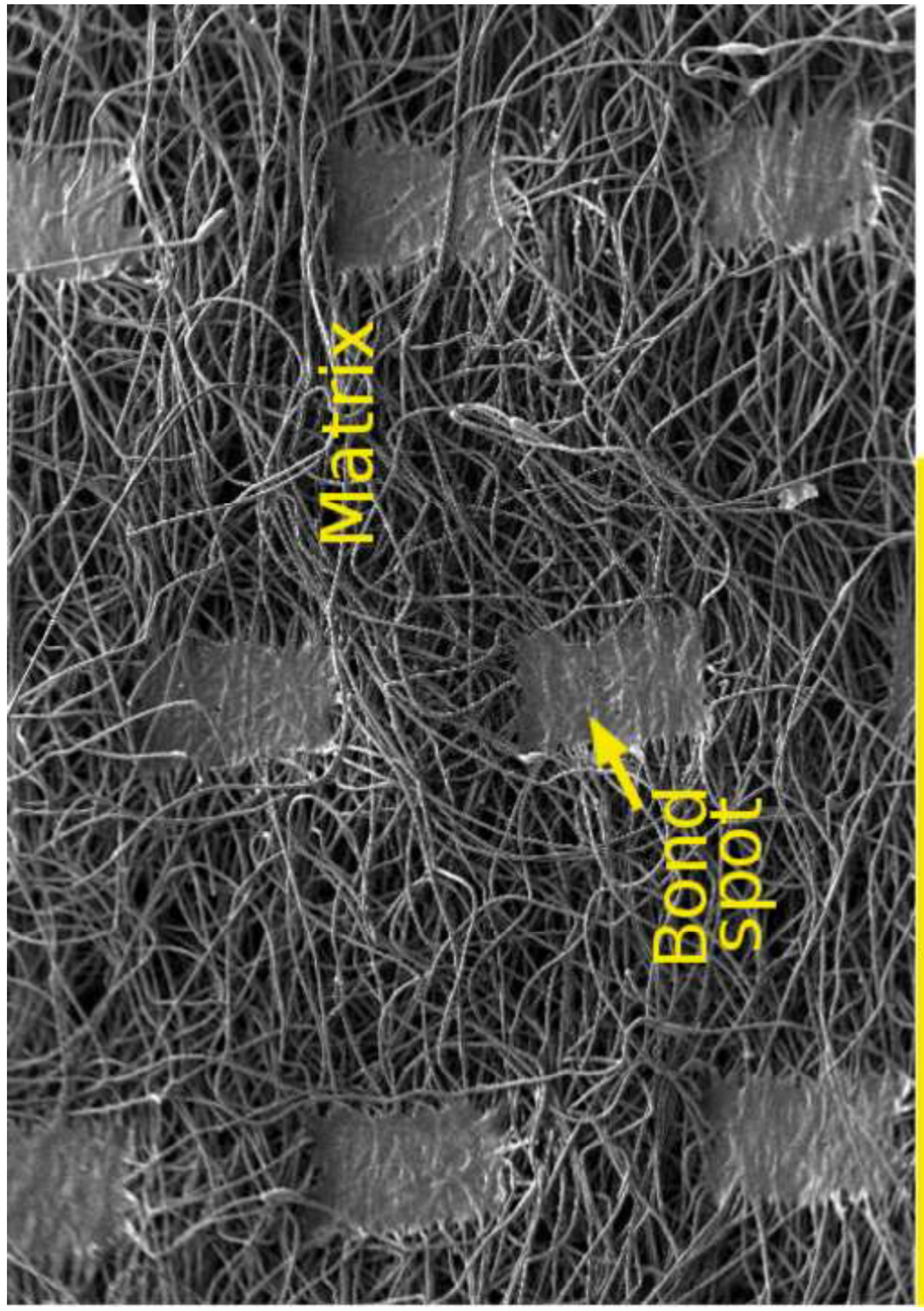




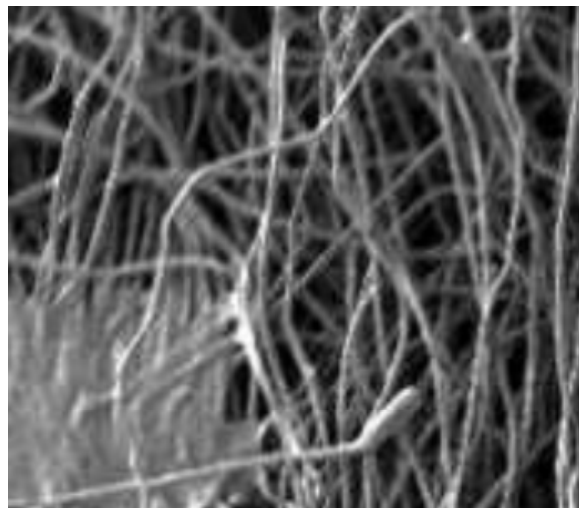

\section{IV}



(5) (a) SWA Iif (T) 3.7 .
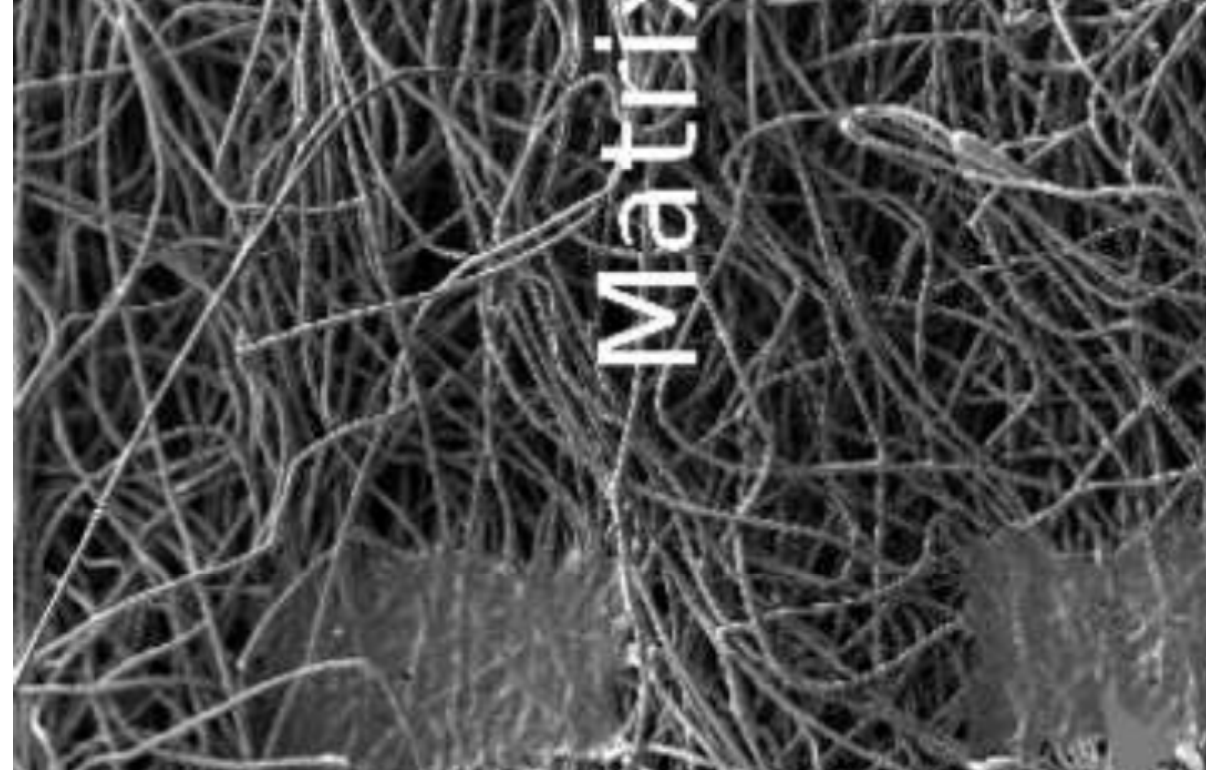
40

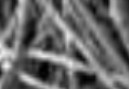

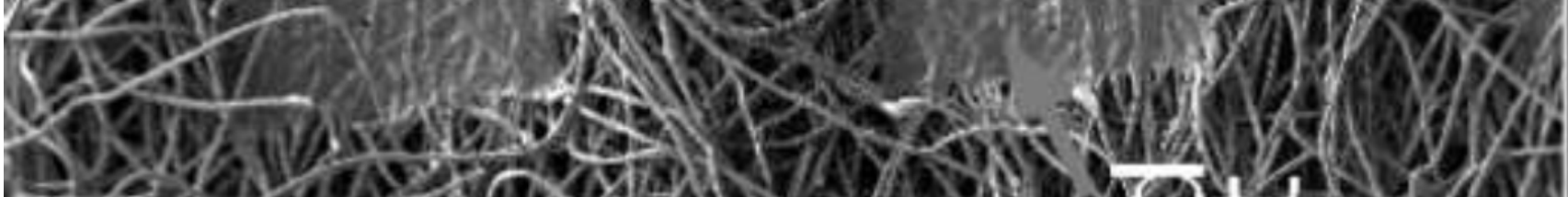


La

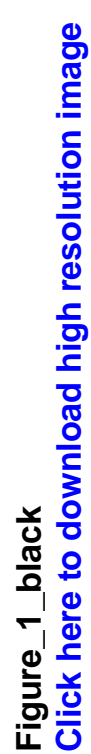

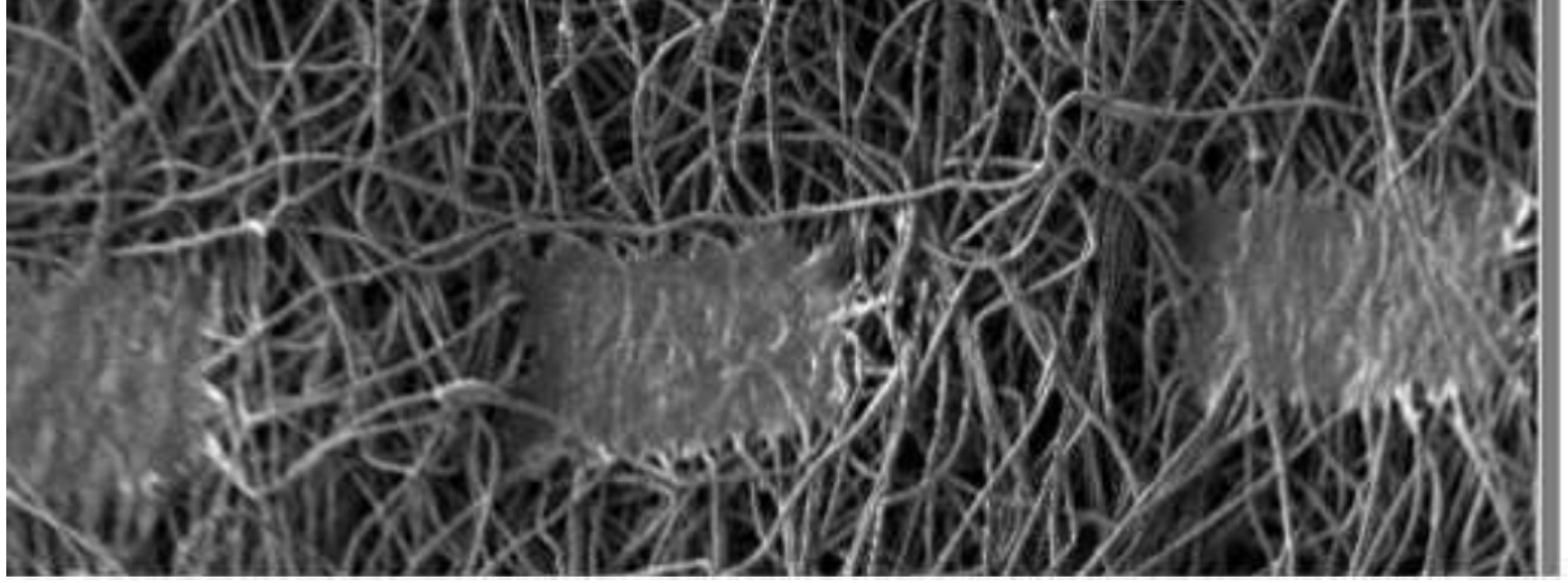




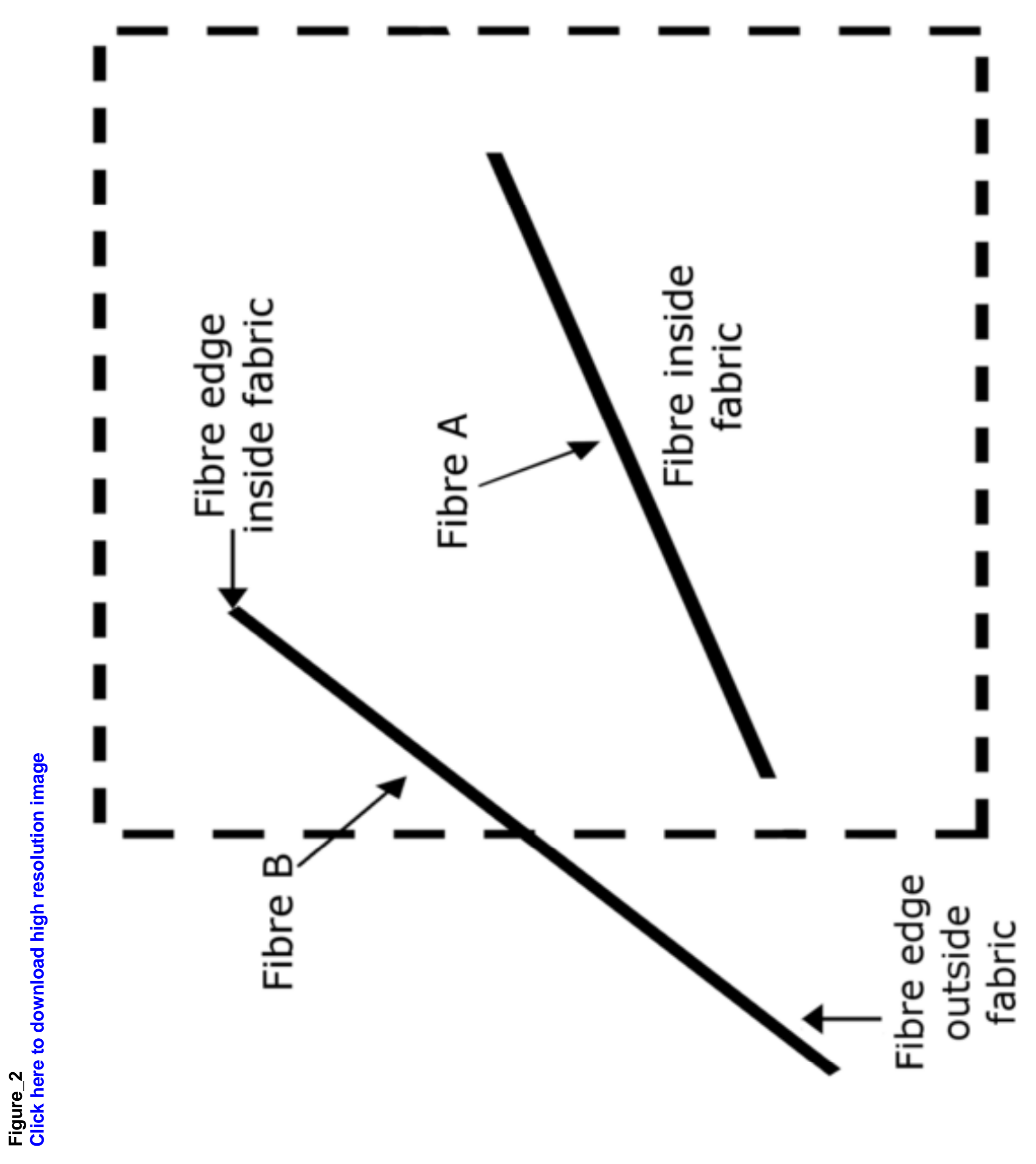



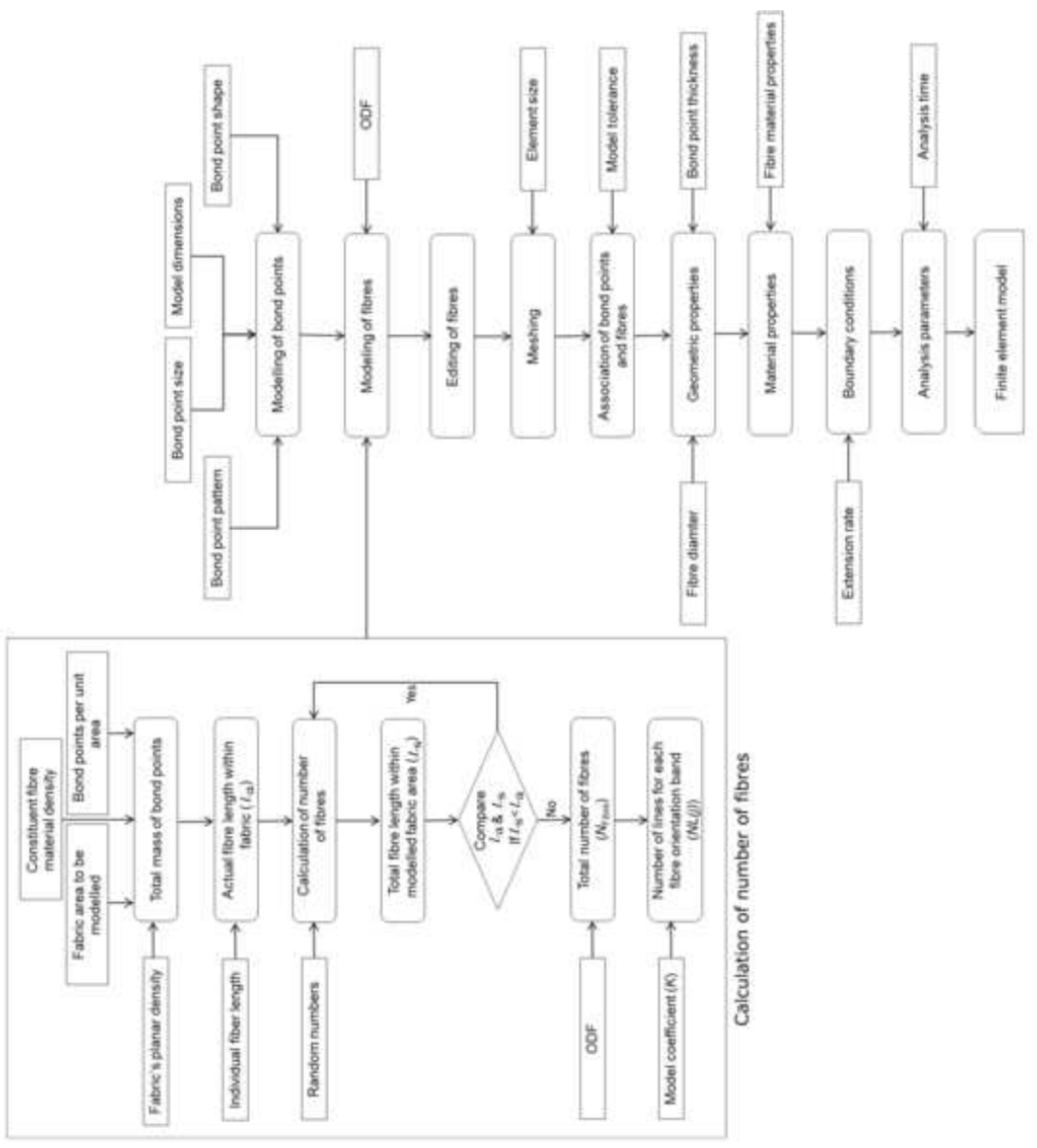

亲尊 







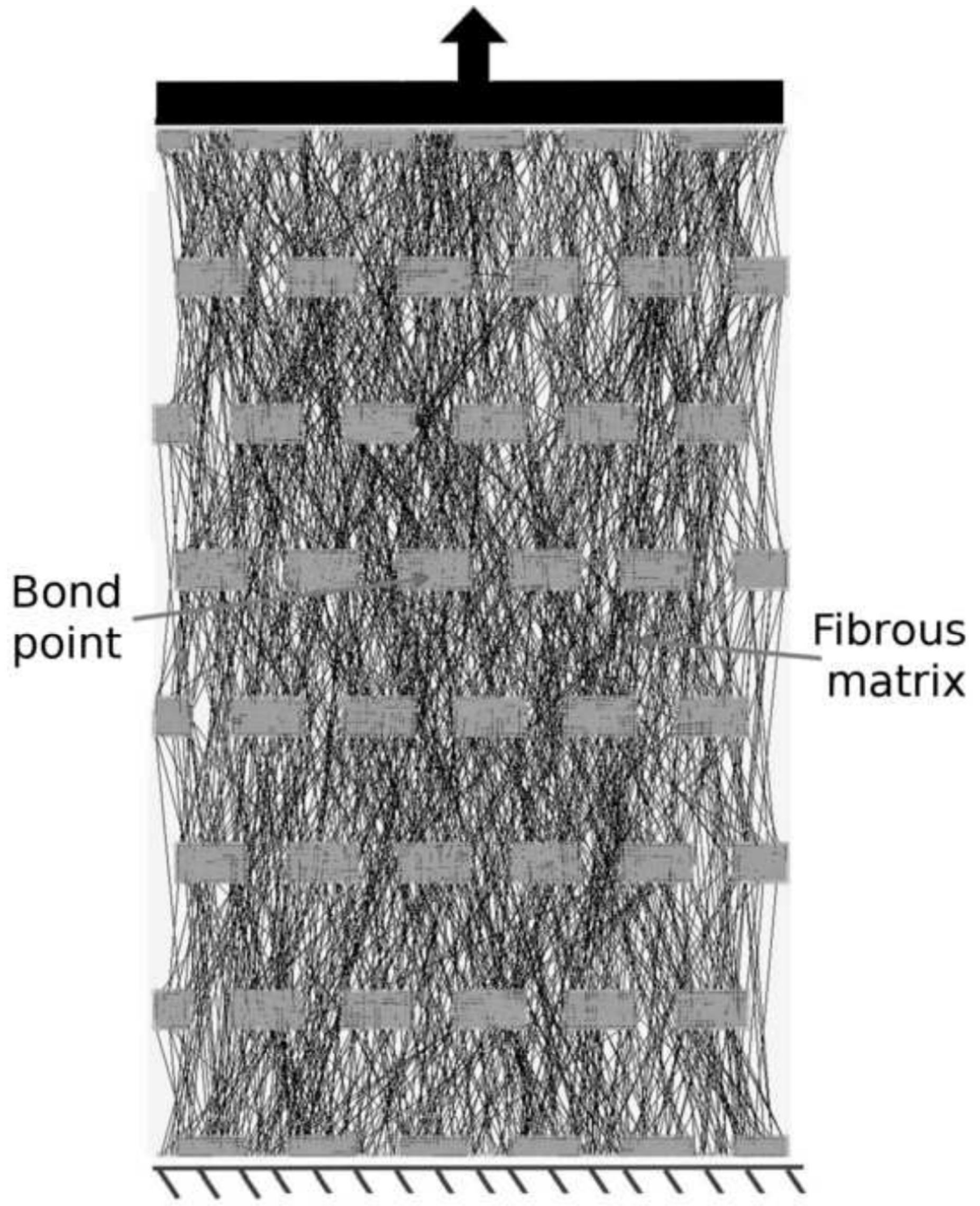




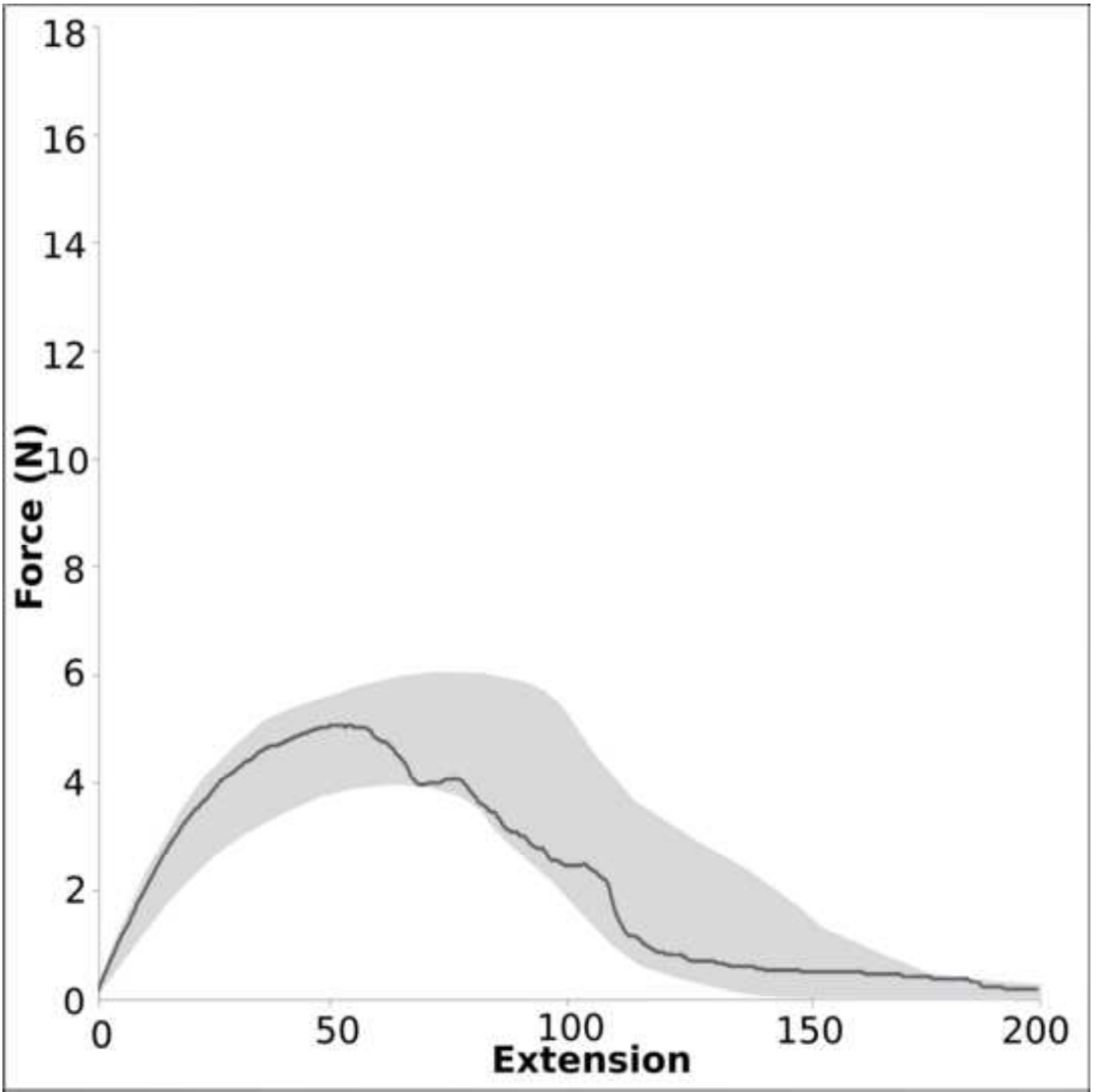




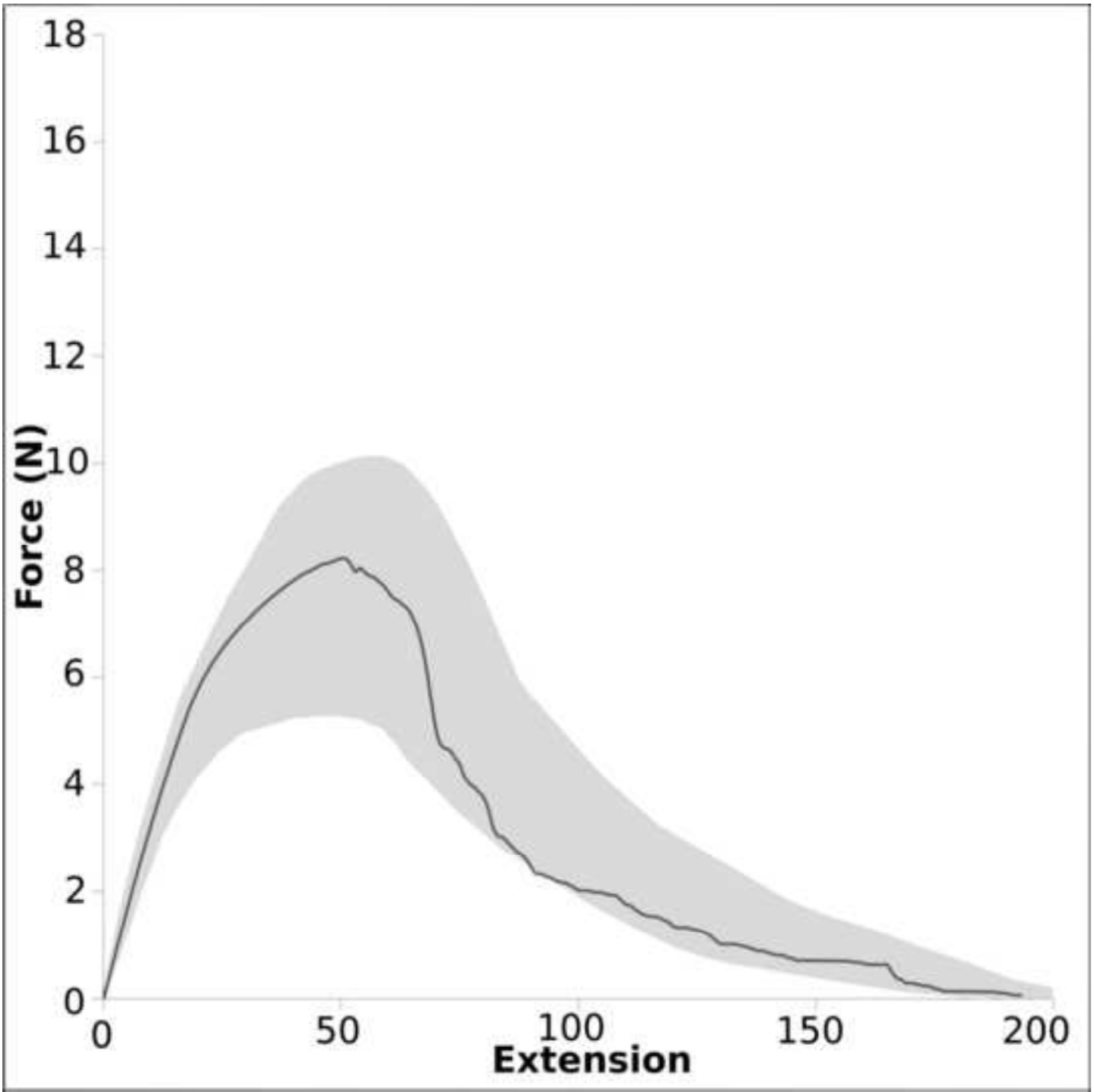




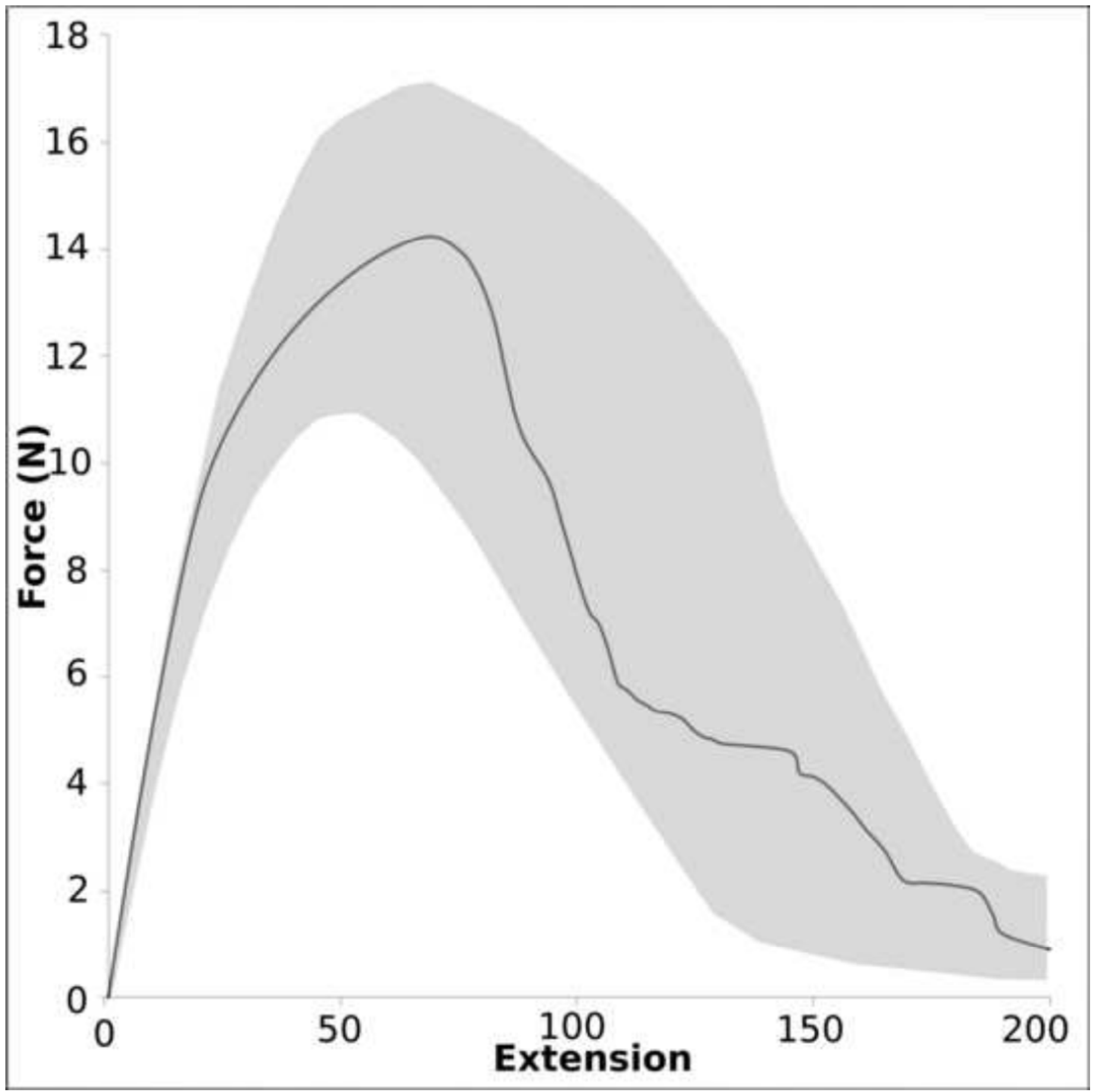




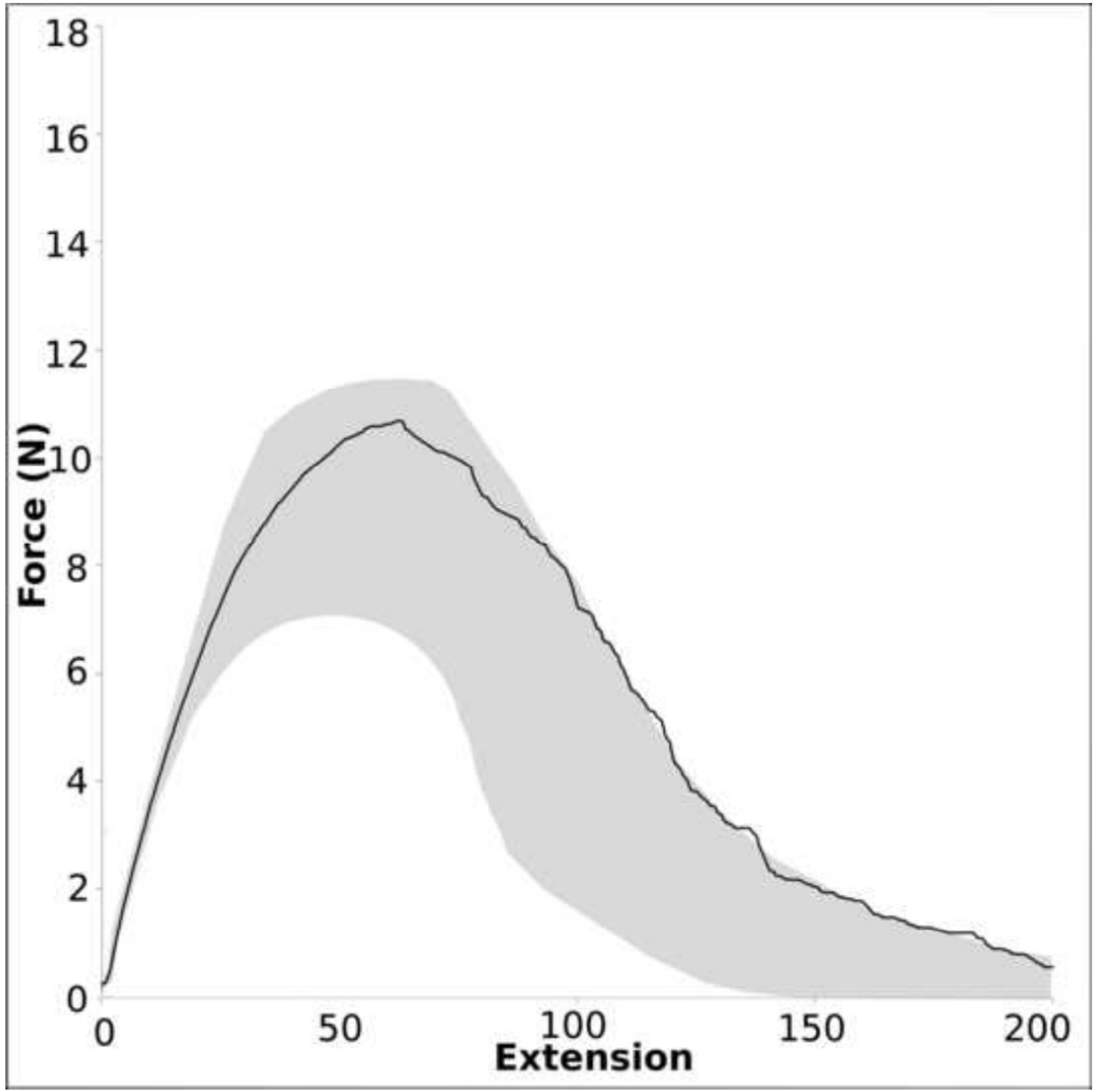




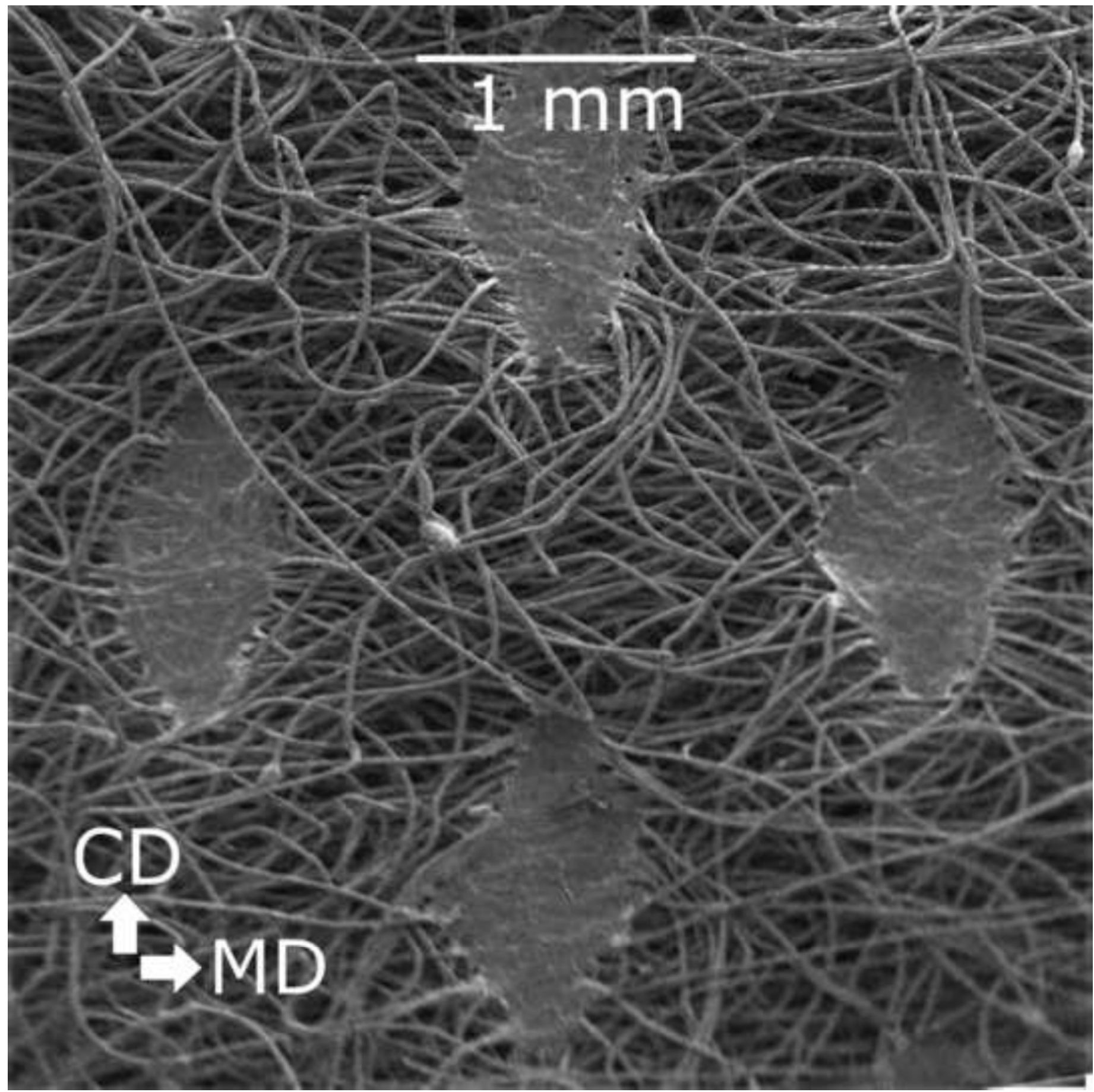




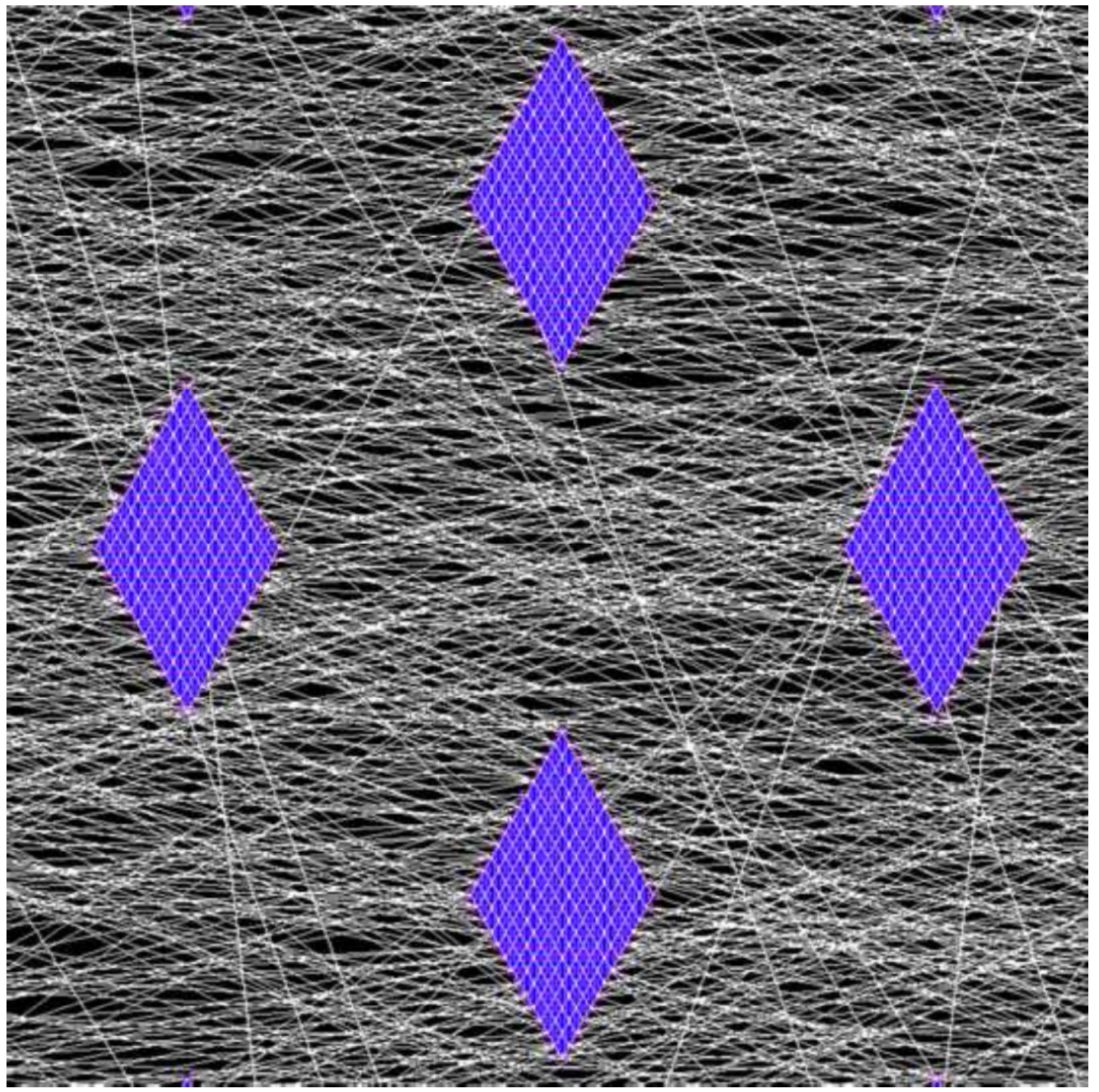




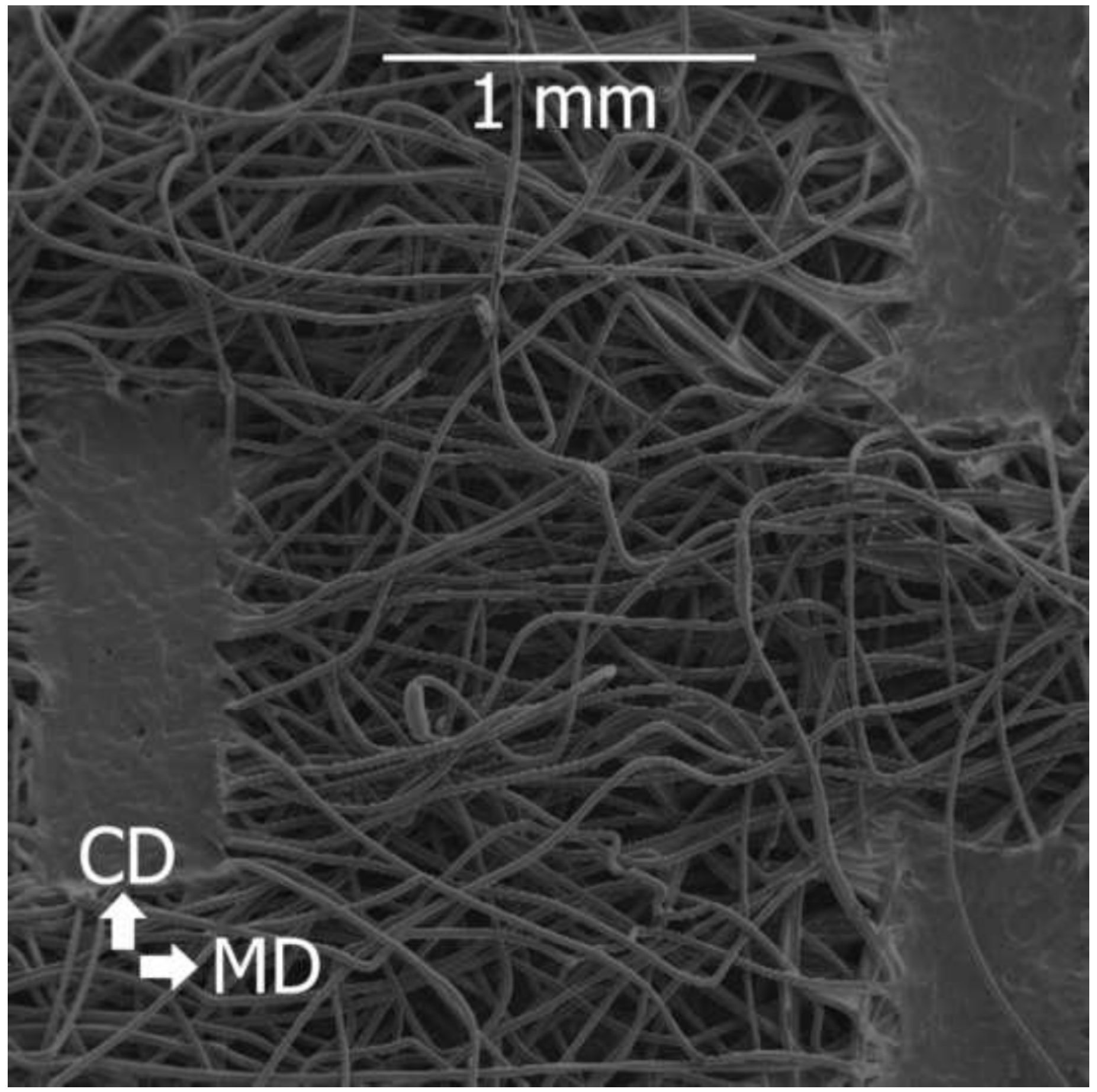


Figure_7d

Click here to download high resolution image

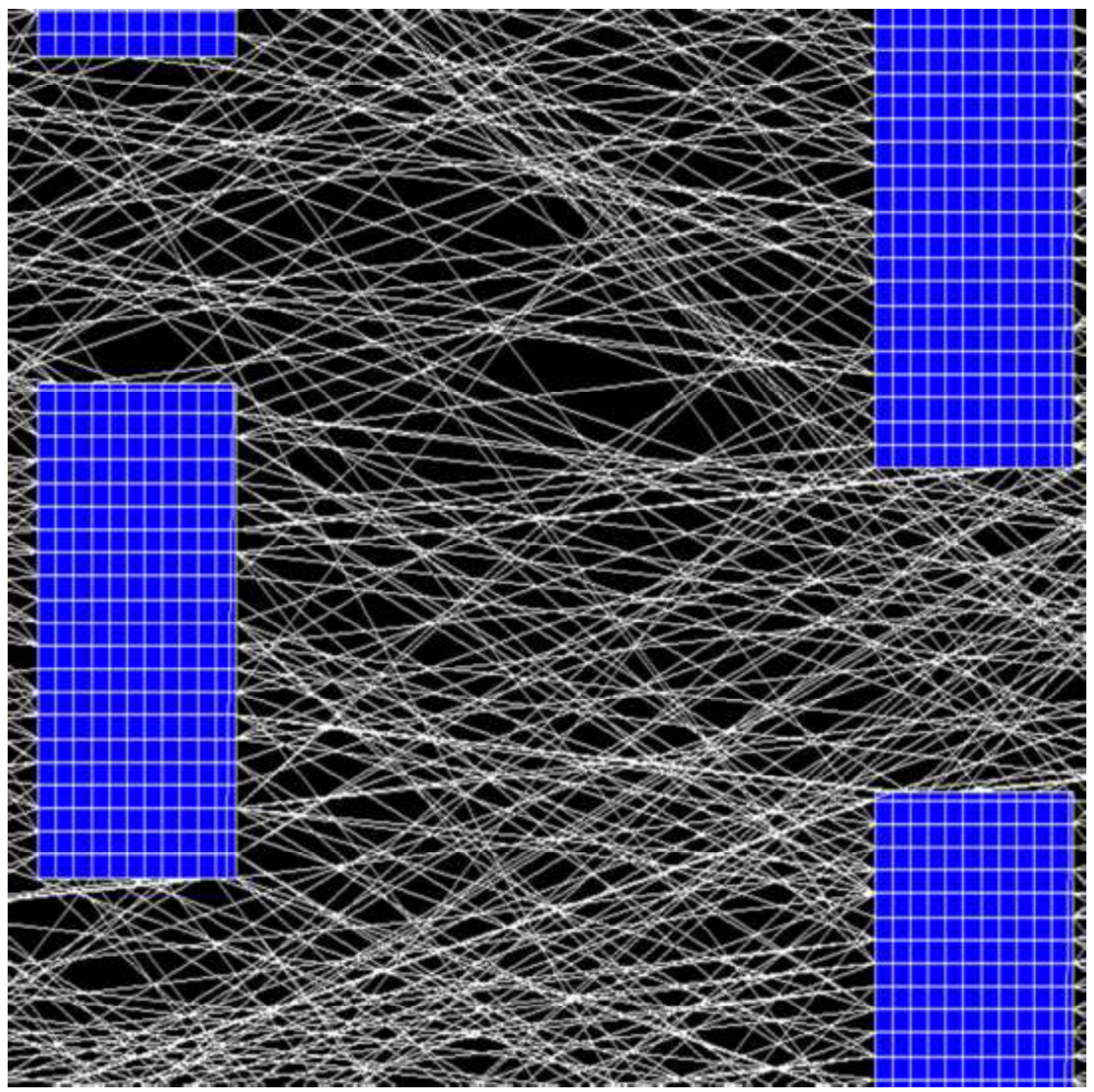




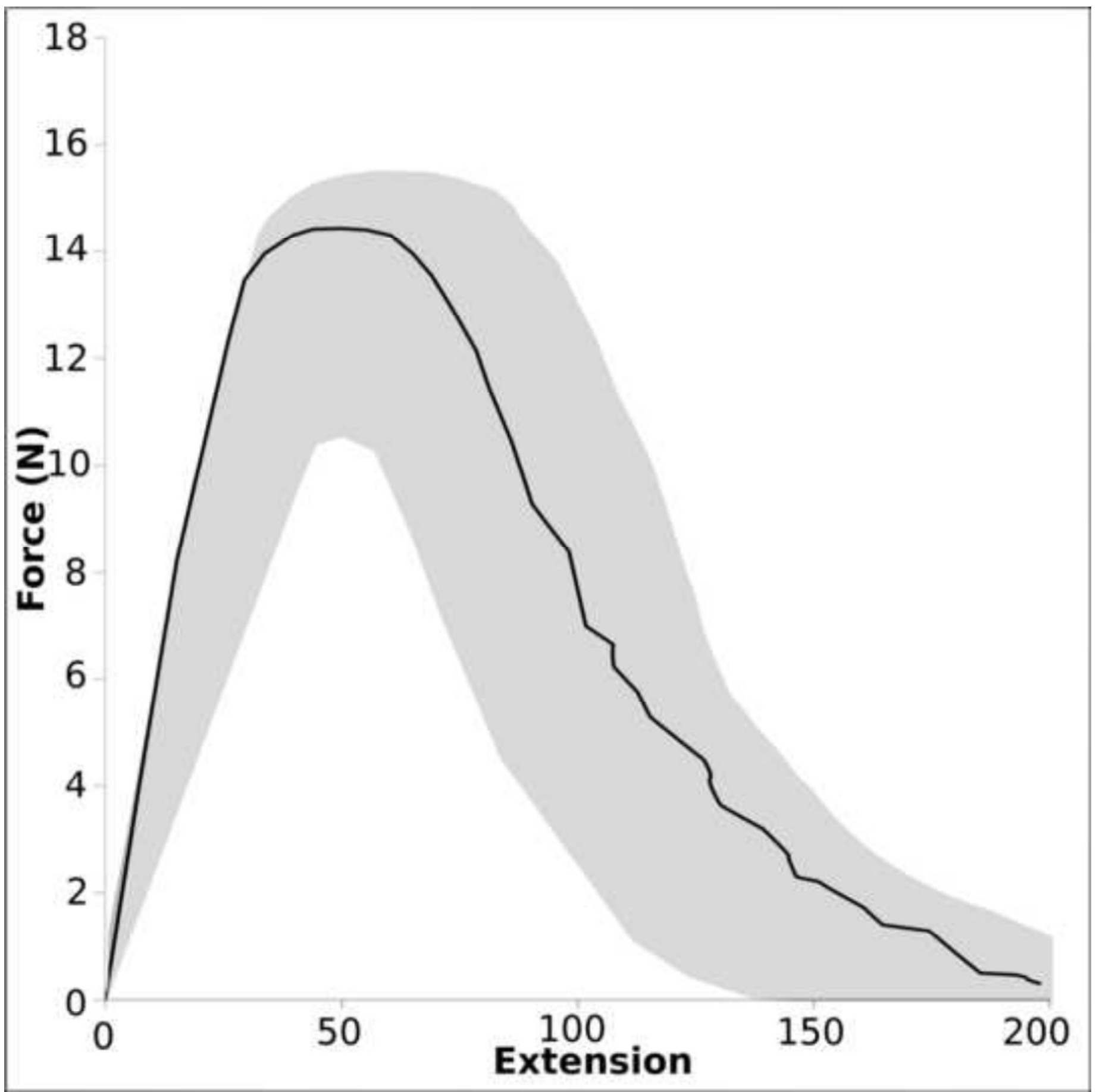




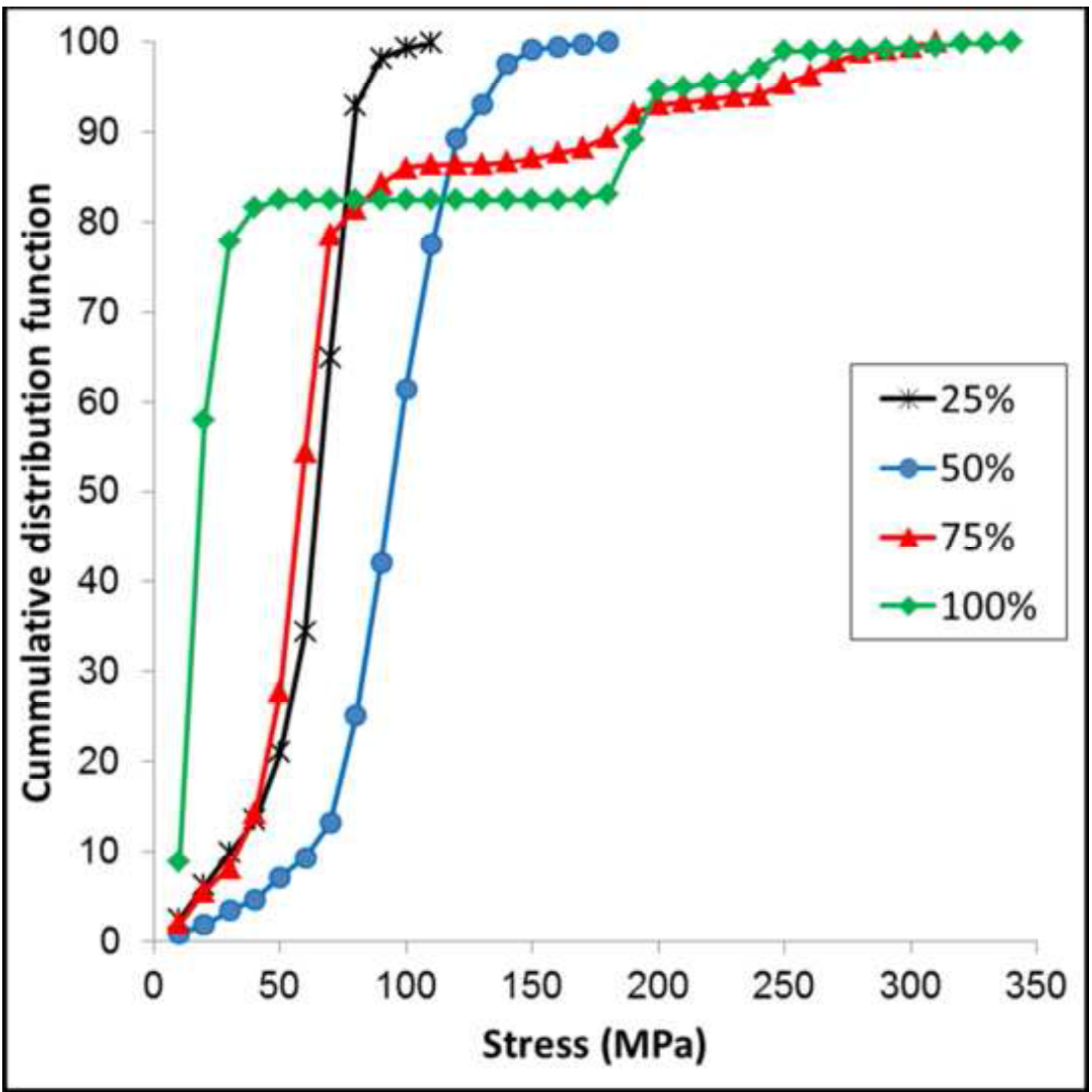




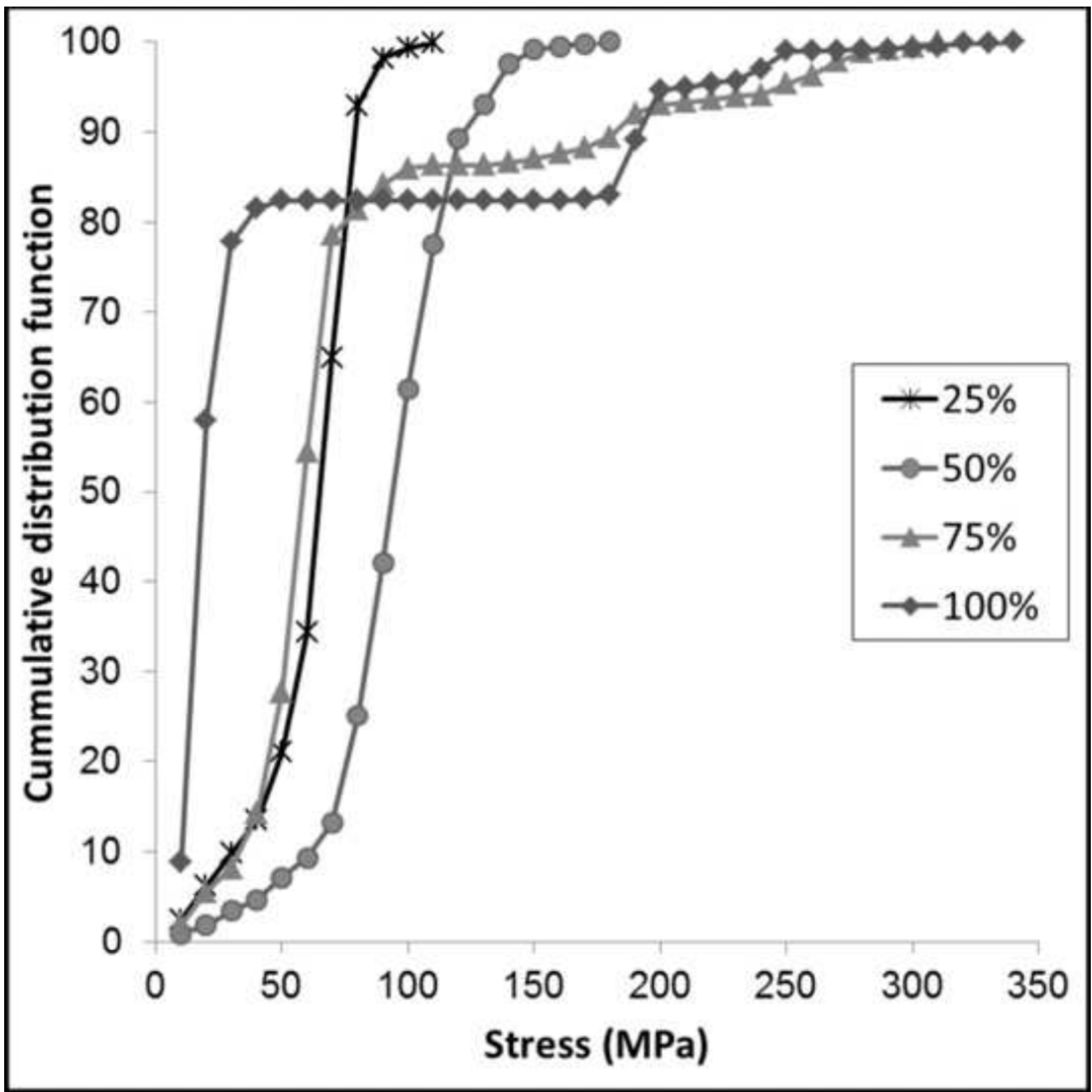



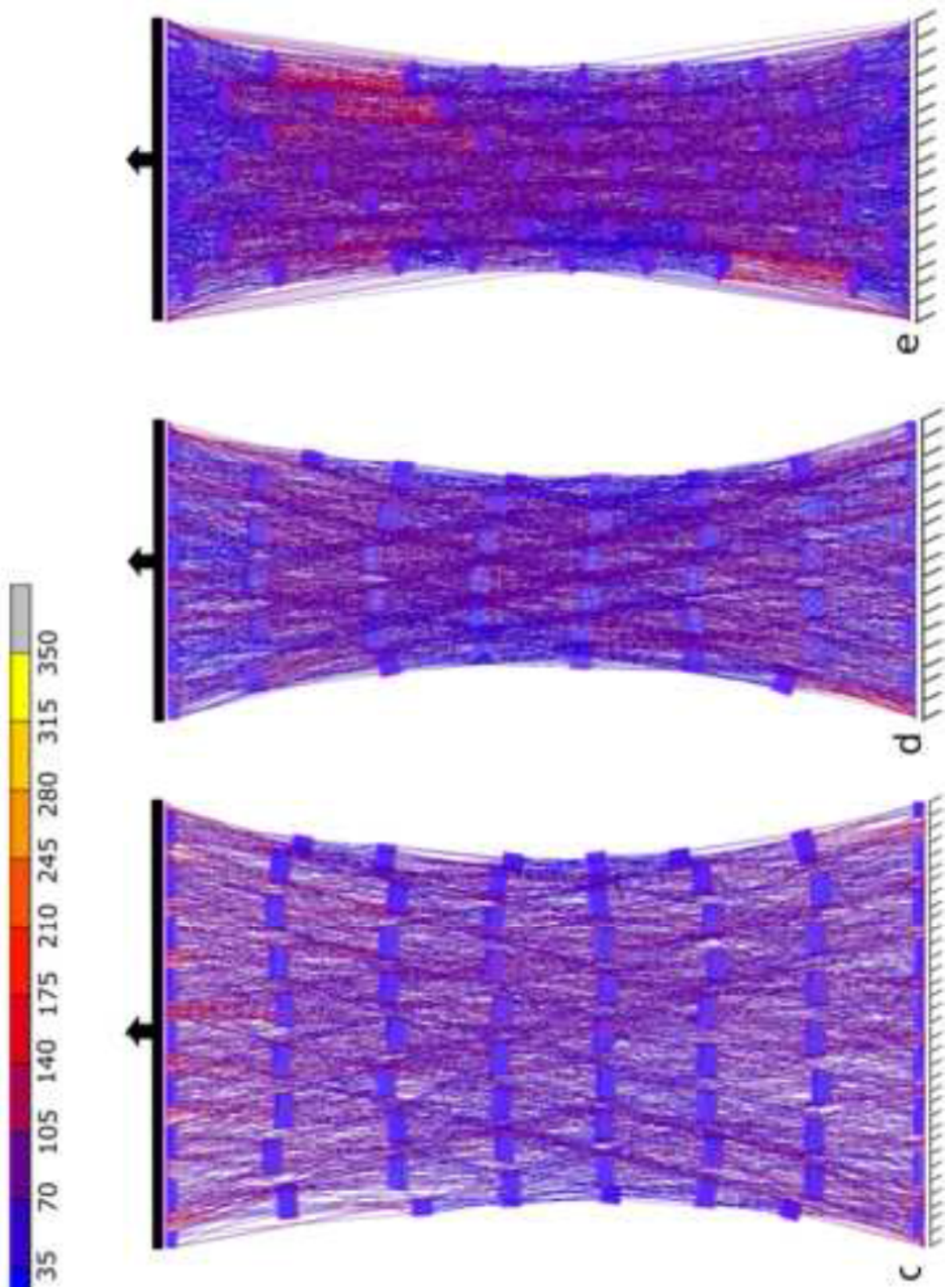

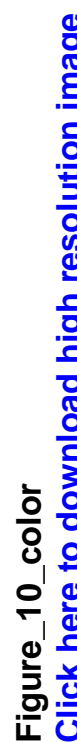
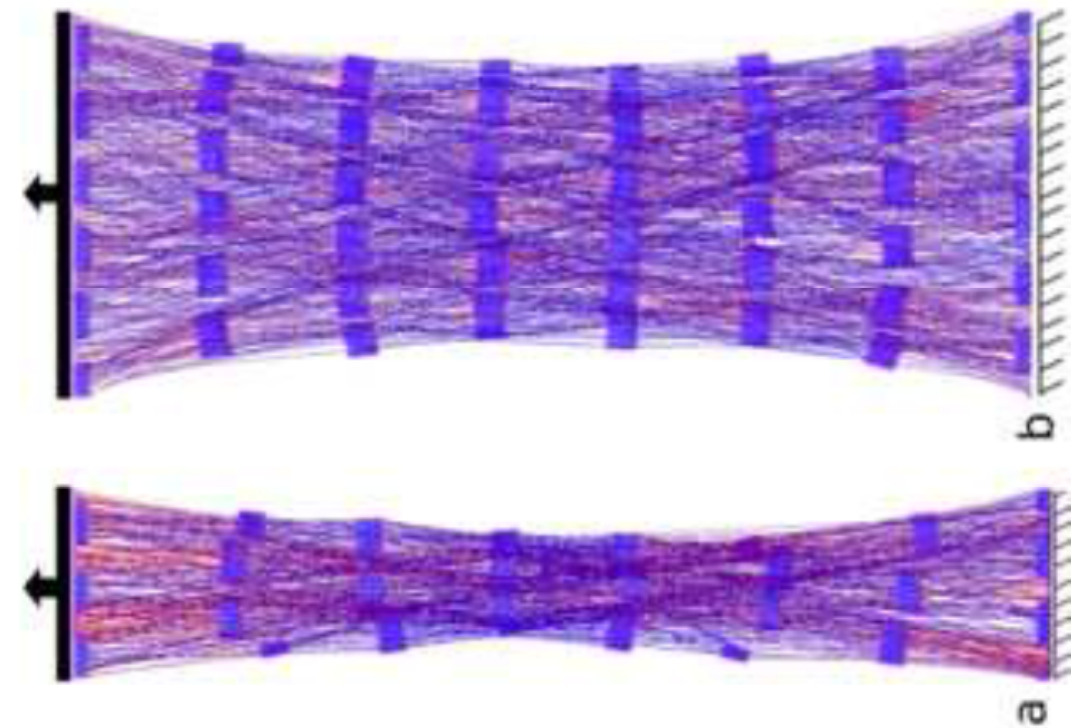



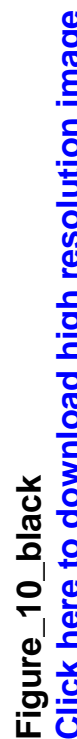
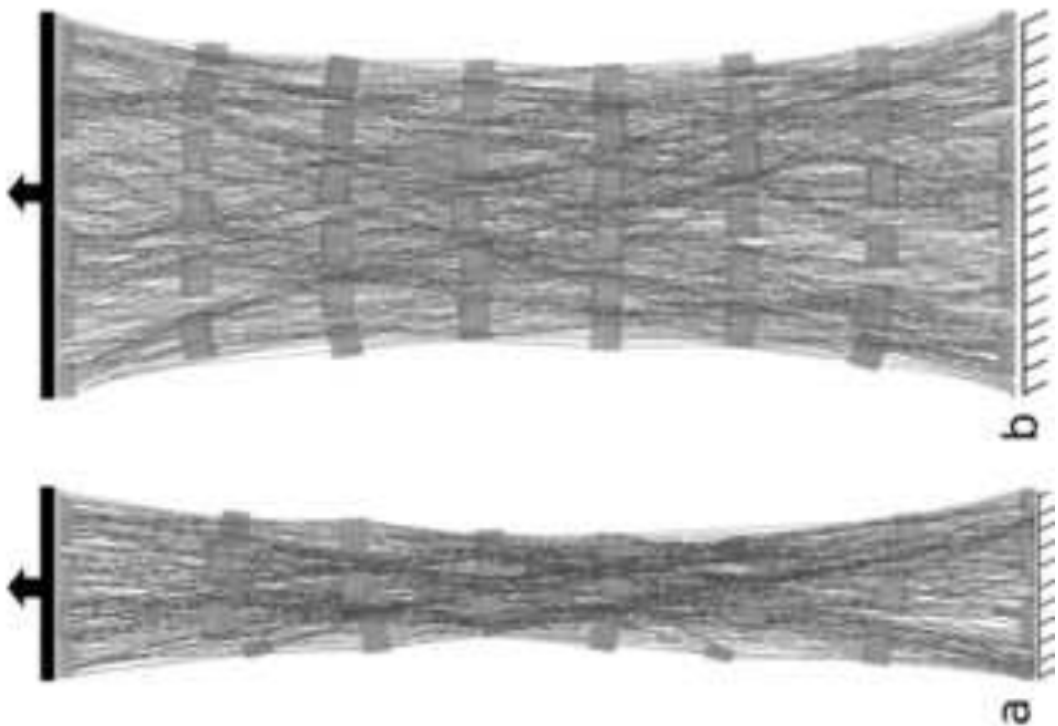

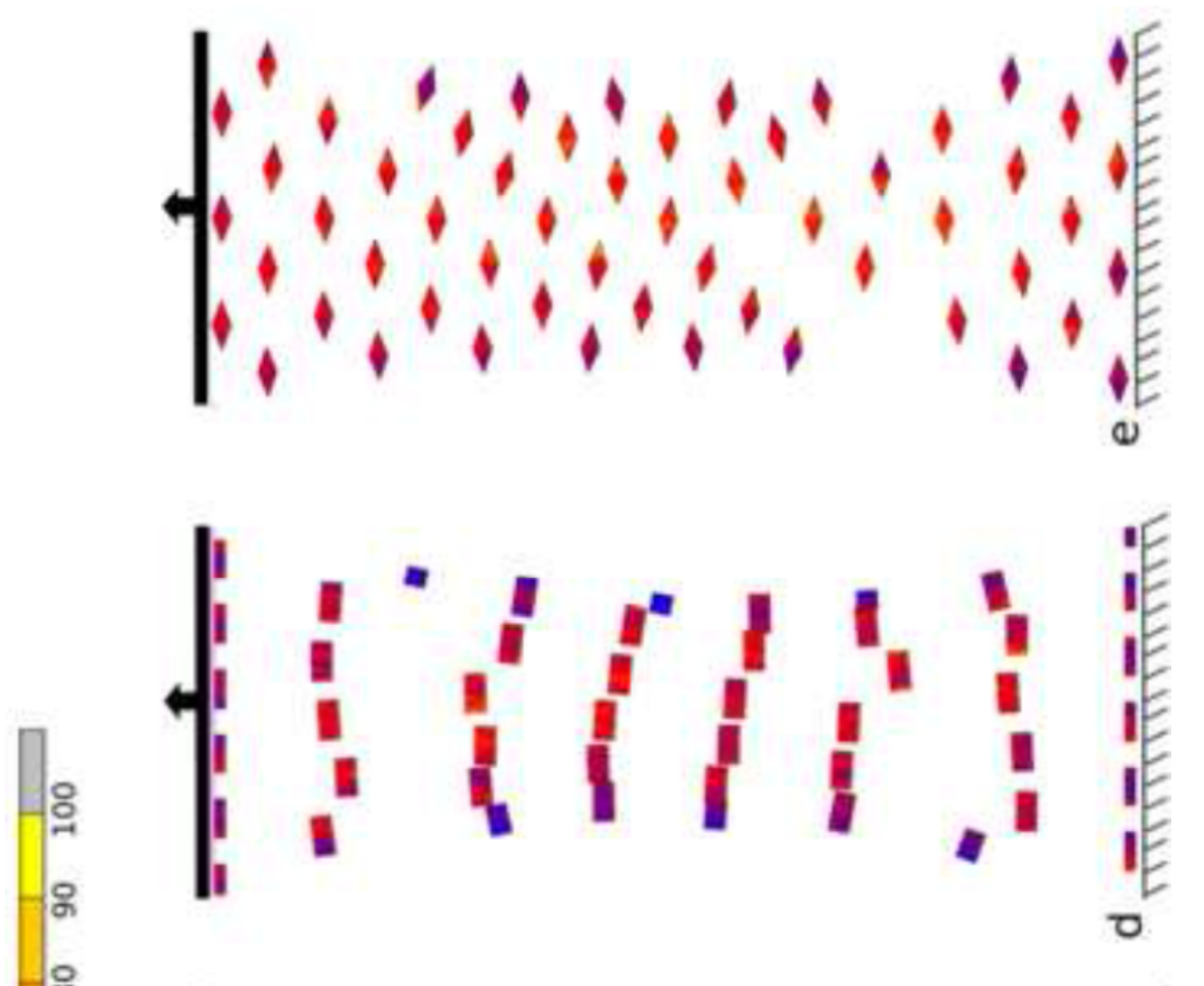

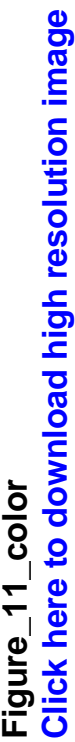

1' 1 1 1

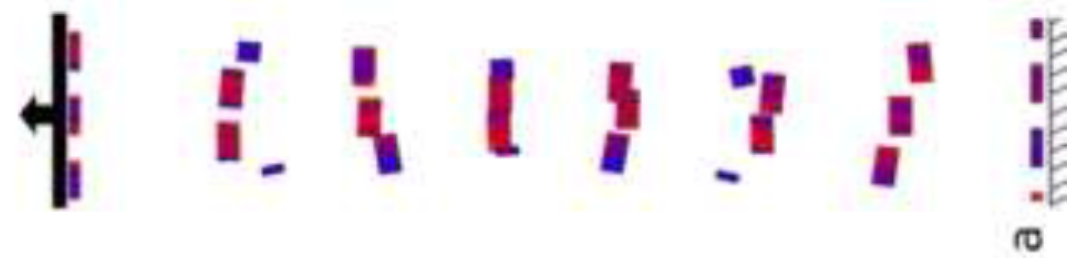


$+4$

|

.

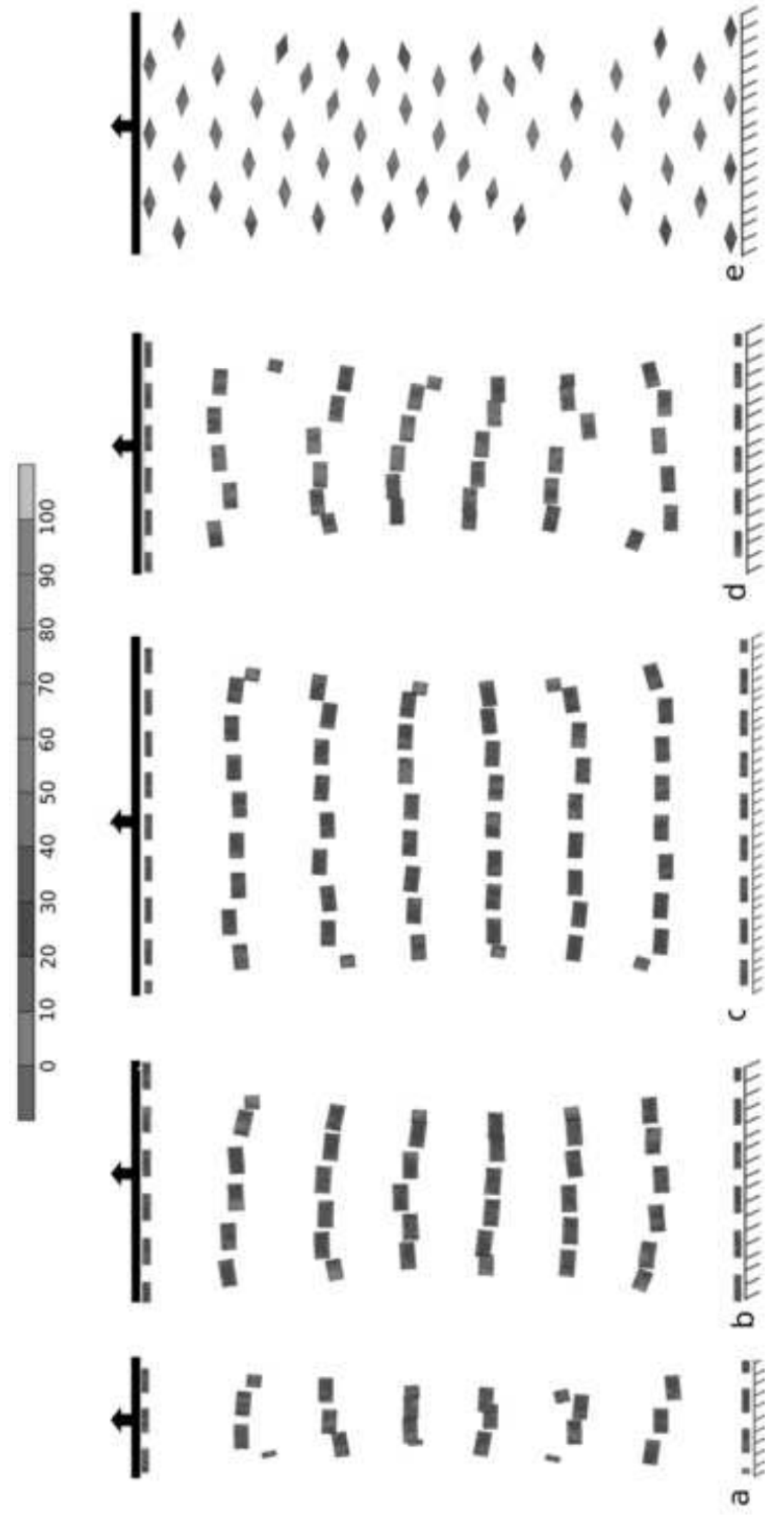


Figure_12

Click here to download high resolution image

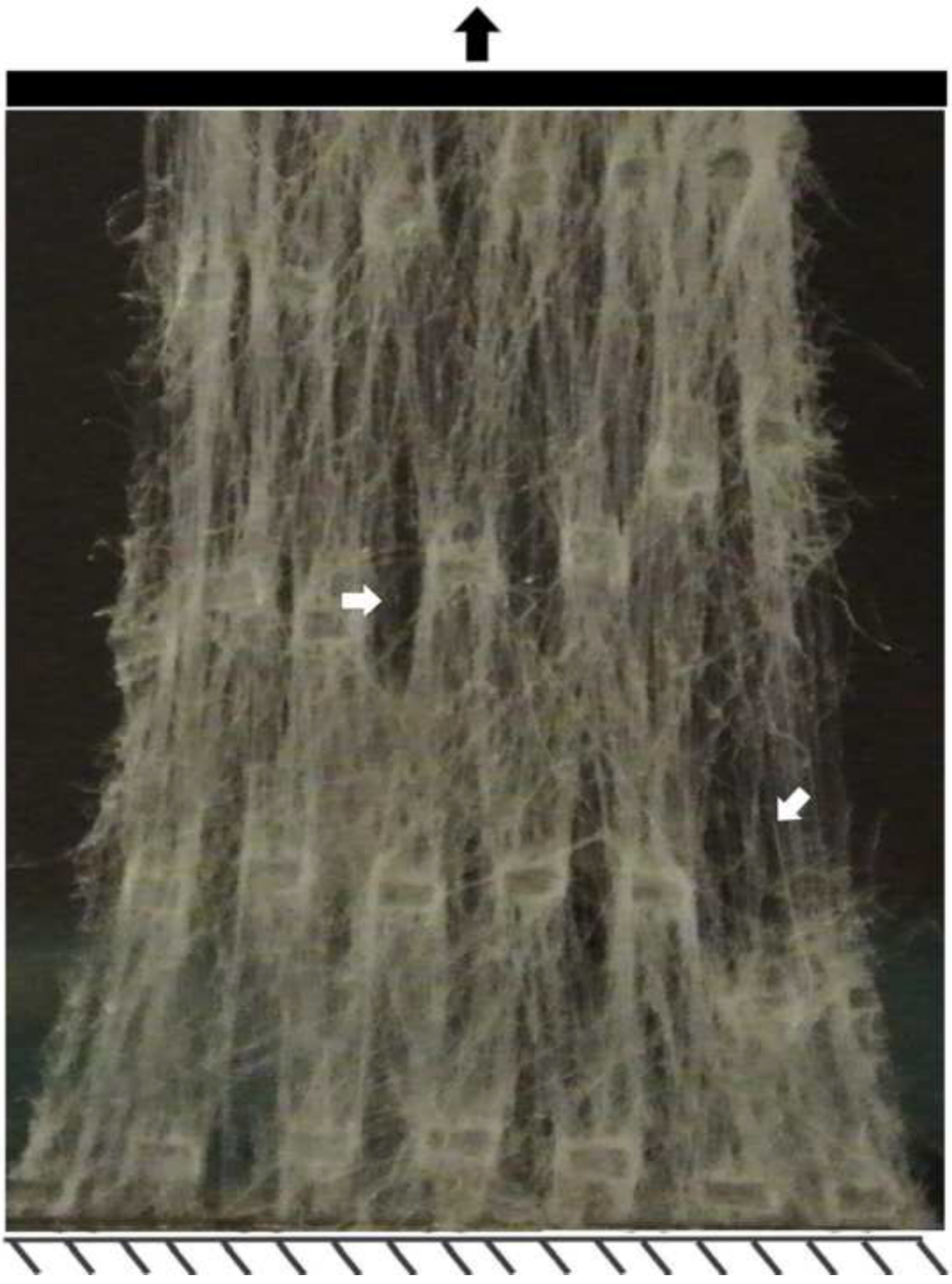

